\title{
Sociality and the Telencephalic Distribution of Corticotrophin-Releasing Factor, Urocortin 3, and Binding Sites for CRF Type 1 and Type 2 Receptors: A Comparative Study of Eusocial Naked Mole-Rats and Solitary Cape Mole-Rats
}

\author{
Clive W. Coen, ${ }^{1 *}$ Theodosis Kalamatianos, ${ }^{1 \dagger}$ Maria K. Oosthuizen, ${ }^{1,2}$ Ravi Poorun, ${ }^{1}$ Christopher G. Faulkes, ${ }^{3}$ \\ and Nigel C. Bennett ${ }^{2}$
}

\footnotetext{
${ }^{1}$ Reproductive Neurobiology, Division of Women's Health, School of Medicine, King's College London, London SE1 1UL, United Kingdom

${ }^{2}$ Department of Zoology and Entomology, University of Pretoria, Pretoria 0002, South Africa

${ }^{3}$ School of Biological and Chemical Sciences, Queen Mary, University of London, London E1 4NS, United Kingdom
}

\begin{abstract}
Various aspects of social behavior are influenced by the highly conserved corticotrophin-releasing factor (CRF) family of peptides and receptors in the mammalian telencephalon. This study has mapped and compared the telencephalic distribution of the CRF receptors, $\mathrm{CRF}_{1}$ and $\mathrm{CRF}_{2}$, and two of their ligands, CRF and urocortin 3, respectively, in African mole-rat species with diametrically opposed social behavior. Naked mole-rats live in large eusocial colonies that are characterized by exceptional levels of social cohesion, tolerance, and cooperation in burrowing, foraging, defense, and alloparental care for the offspring of the single reproductive female. Cape molerats are solitary; they tolerate conspecifics only fleetingly during the breeding season. The telencephalic sites at which the level of $\mathrm{CRF}_{1}$ binding in naked mole-rats exceeds that in Cape mole-rats include the basolateral
\end{abstract}

amygdaloid nucleus, hippocampal CA3 subfield, and dentate gyrus; in contrast, the level is greater in Cape molerats in the shell of the nucleus accumbens and medial habenular nucleus. For $\mathrm{CRF}_{2}$ binding, the sites with a greater level in naked mole-rats include the basolateral amygdaloid nucleus and dentate gyrus, but the septohippocampal nucleus, lateral septal nuclei, amygdalostriatal transition area, bed nucleus of the stria terminalis, and medial habenular nucleus display a greater level in Cape mole-rats. The results are discussed with reference to neuroanatomical and behavioral studies of various species, including monogamous and promiscuous voles. By analogy with findings in those species, we speculate that the abundance of $\mathrm{CRF}_{1}$ binding in the nucleus accumbens of Cape mole-rats reflects their lack of affiliative behavior.

INDEXING TERMS: naked mole-rats; Heterocephalus glaber; Cape mole-rats; Georychus capensis; corticotrophinreleasing factor (CRF); corticotrophin-releasing hormone (CRH); urocortin; social behavior; cooperation; nucleus accumbens; cerebral cortex; hippocampus; septum; bed nucleus of the stria terminalis; amygdala; habenula

The corticotrophin-releasing factor (CRF) family of peptides and receptors has been highly conserved over vertebrate evolution (Chang and Hsu, 2004). In addition to the neuroendocrine actions of CRF and its type 1 receptor in the anterior pituitary gland, the cognate peptides and receptors in the central nervous system contribute to diverse networks that regulate arousal, emotionality, and responses to stress (Bale and Vale, 2004; Heinrichs and Koob, 2004). These networks influence social behavior by their effects on aggression,
Grant sponsor: Biotechnology and Biological Sciences Research Council; Grant number: BBD5231861 (to C.W.C., C.G.F.); Grant sponsor: National Research Foundation (to N.C.B.); University of Pretoria (to N.C.B.).

*CORRESPONDENCE TO: Clive W. Coen, Reproductive Neurobiology, Division of Women's Health, School of Medicine, King's College London, London SE1 1UL, United Kingdom. E-mail: clive.coen@kcl.ac.uk

${ }^{\dagger}$ Current address: Department of Neurosurgery, University of Athens Medical School, Greece 
submission, affiliation, memory consolidation, recognition, pair-bonding, and parental care, as comprehensively reviewed by Hostetler and Ryabinin (2013). In mammals, the CRF-related networks involve four ligands, CRF, urocortin 1 (Ucn 1), Ucn 2, and Ucn 3, and two receptors, $\mathrm{CRF}_{1}$ and $\mathrm{CRF}_{2}$ (Hauger et al., 2003). CRF and Ucn 1 bind to $\mathrm{CRF}_{1}$ with high affinity; in contrast, Ucn $1, \operatorname{Ucn} 2$, and $U \mathrm{cn} 3$ bind to $\mathrm{CRF}_{2}$ with affinities that are up to 100 -fold higher than that for CRF (Hauger et al., 2003). Thus, whereas CRF is classified as a ligand for $\mathrm{CRF}_{1}$, with a moderate affinity for $\mathrm{CRF}_{2}$, and Ucn 2 and Ucn 3 are classified as selective ligands for $\mathrm{CRF}_{2}$, Ucn 1 is considered to be a ligand for both receptors (Hauger et al., 2003).

Comparative studies of vole species have helped to elucidate the social functions of CRF receptors in the telencephalon (Lim et al., 2005). Prairie and pine voles are monogamous, pair-bonding, and cooperative in their care for offspring (alloparental); in contrast, meadow and montane voles are solitary, promiscuous, and nonpair-bonding. The monogamous species have lower levels of $\mathrm{CRF}_{1}$ binding and higher levels of $\mathrm{CRF}_{2}$ binding in the nucleus accumbens than the promiscuous species (Lim et al., 2005).

To extend our understanding of the involvement of the CRF-related networks in social behavior, the present study focuses on African mole-rats, which belong to the hystricognath suborder of rodents. These microphthalmic, subterranean species provide a unique taxonomic group for investigating the neurobiology and evolution of mammalian social behavior. The two members of the Bathyergidae family of species that have been studied here differ to an extreme degree in their social behavior.

Naked mole-rats (Heterocephalus glaber) are designated as eusocial and represent the pinnacle of mammalian sociality (Jarvis, 1981). Within a colony, which may number up to 300 animals in the wild, naked mole-rats exhibit remarkable levels of social cohesion and tolerance. Breeding is monopolized by a single reproductive female, the socially dominant queen, and her one to three male consorts; most members of the colony never enter puberty and remain nonreproductive throughout life (Jarvis, 1991; Zhou et al., 2013). The aridity of their habitat confers risks and high energy costs on underground foraging for roots and tubers and thereby favors cooperation (Jarvis et al., 1994; Faulkes et al., 1997; Bennett et al., 1999). Subordinate, nonbreeding colony members participate in a broad range of cooperative behaviors, including burrowing, foraging, alloparenting, and defending the colony against predators and foreign conspecifics (Jarvis, 1981; Faulkes et al., 1991; Lacey and Sherman, 1991). The degree of social tolerance toward unrelated or unfamiliar conspecifics varies with reproductive status; breeding males and nonbreeders of both sexes are normally xenophobic and attack unfamiliar conspecifics (Lacey and Sherman, 1991; O'Riain and Jarvis, 1997), but breeding females prefer to mate with unfamiliar and unrelated individuals (Clarke and Faulkes, 1999; Braude, 2000; Ciszek, 2000).

In contrast to naked mole-rats, Cape mole-rats (Georychus capensis) are virtually asocial; within their mesic habitat, the more uniform distribution of food and the lower energy costs of burrowing through rainmoistened soil favor a solitary life style (Jarvis et al., 1994). Interactions with conspecifics are restricted to fleeting encounters and copulation during the rainy season, when males and females attract one another with elaborate seismic signals, and to short-lived contacts between mother and pups or between littermates (Bennett and Jarvis, 1988; Narins et al., 1992; Ganem and Bennett, 2004).

Associations between certain ecological constraints and the distribution of species with distinct social phenotypes led to the aridity-food distribution hypothesis for the evolution of sociality in the Bathyergidae (Jarvis et al., 1994; Faulkes et al., 1997, 2004; Faulkes and Bennett, 2013). Others have argued against this and proposed that a monogamous mating system was ancestral to the eusociality and restricted monogyny that characterize naked mole-rat colonies (Burda et al., 2000); counterargument has also been provided (Faulkes and Bennett, 2007; O'Riain and Faulkes, 2008). Nevertheless, the idea of ancestral monogamy offers an additional perspective for comparisons between eusocial and solitary mole-rats and monogamous and promiscuous voles. In a previous study (Kalamatianos et al., 2010), we found one site at which the difference in oxytocin receptor binding distribution between eusocial and solitary mole-rats is strikingly similar to that between monogamous and polygamous voles; the nucleus accumbens displays a greater level of oxytocin receptor binding in the eusocial and monogamous species, possibly reflecting their prosocial behaviors. Whether such similarities are due to gene conservation or convergent evolution remains to be determined.

The present study maps and compares the telencephalic distribution of the CRF receptors, $\mathrm{CRF}_{1}$ and $\mathrm{CRF}_{2}$, and two of their ligands, CRF and Ucn 3, respectively, in African mole-rat species with diametrically opposed social behavior. In discussing the results with reference to neuroanatomical and behavioral findings in various species, we address the possibility that some of the differences between these Old World eusocial and 
solitary mole-rats are analogous to those previously identified between monogamous and promiscuous New World voles.

\section{MATERIALS AND METHODS}

\section{Animals and tissue collection}

The animals investigated in this study were adult male nonreproductive naked mole-rats (ligand binding study, $n=5$; immunohistochemistry study, $n=4)$, which had been bred at Queen Mary, University of London, and housed in their natal colonies as previously described (Faulkes et al., 1991), and adult male Cape mole-rats (ligand binding study, $n=5$; immunohistochemistry study, $n=4$ ), which had been trapped during the nonbreeding season in Darling, South Western Cape, South Africa, and housed individually for a maximum of 2 weeks at the Department of Zoology and Entomology, University of Pretoria. We have previously reported that naked mole-rats show similar behavior and reproductive physiology whether wild or captive bred (Faulkes et al., 1990; Sherman et al., 1991). Cape mole-rats, unlike naked mole-rats, cannot be bred in captivity. For the ligand binding study, animals were killed by decapitation under deep isofluorane (Zeneca, Johannesburg, RSA; Abbott Laboratories, Ltd., Maidenhead, United Kingdom) anesthesia. The brain was rapidly removed, frozen on dry ice, and stored at $-80^{\circ} \mathrm{C}$. For the immunohistochemical study, animals, under anesthesia induced by sodium pentobarbitone (Pentoject; Animalcare, Ltd., York, United Kingdom; $50 \mathrm{mg} / \mathrm{kg}$ ) or fluorothane (Zeneca, RSA), were perfused transcardially with phosphate-buffered saline (PBS), followed by $4 \%$ paraformaldehyde in $0.1 \mathrm{M}$ phosphate buffer ( $\mathrm{pH}$ 7.4). The brain was removed, postfixed overnight in the same fixative, and saturated with $30 \%$ sucrose. Nonreproductive status was verified by examination of the reproductive tract as previously described (Bennett and Jarvis, 1988). The research was conducted in accordance with the U.K. Home Office Animals (Scientific Procedures) Act 1986 and with the regulations of the University of Pretoria's Animal Ethics Committee (ethics clearance No. 000418-006).

\section{$\mathrm{CRF}_{1}$ and $\mathrm{CRF}_{2}$ ligand binding autoradiography}

Each telencephalon was cut into serial coronal sections $(20 \mu \mathrm{m})$ with a cryostat. Two adjacent sections were thaw mounted onto Superfrost Plus slides (SigmaAldrich, Poole, United Kingdom) in four rostrocaudal series for each animal. They were allowed to air dry at room temperature and stored at $-80^{\circ} \mathrm{C}$. To start the ligand binding autoradiographic procedure, the slides were brought to room temperature and immersed in freshly prepared $0.1 \%$ paraformaldehyde in PBS $(\mathrm{pH}$ 7.4) for 2 minutes; they were then rinsed three times in Tris- $\mathrm{HCl}$ (Sigma-Aldrich) buffer ( $\mathrm{pH}$ 7.4). Adjacent sets of slides were processed for $\mathrm{CRF}_{1}$ and $\mathrm{CRF}_{2}$ binding. The recently published naked mole-rat genome (Yu et al., 2011; Kim et al., 2011; GenBank nif-0000-02873) shows high similarity in the amino acid sequences for naked mole-rat $\mathrm{CRF}_{1}$ (XP_004868724.1) and rat $\mathrm{CRF}_{1}$ (NP_112261.1, 92\%), human $\mathrm{CRF}_{1}$ (NP_001138620.1, 97\%), prairie vole $\mathrm{CRF}_{1}$ (XP_005369449.1, 93\%), or sheep $\mathrm{CRF}_{1}$ (NP_001009727.1, 93\%) and for naked mole-rat $\mathrm{CRF}_{2}$ (XM_004839471.1), rat $\mathrm{CRF}_{2}$ (XP_006236618.1, $89 \%$ ), human $\mathrm{CRF}_{2}$ (NP_001189404.1, 89\%), prairie vole $\mathrm{CRF}_{2}$ (XP_005360866.1, 87\%), or sheep $\mathrm{CRF}_{2}$ (XP_004007977.1, 95\%). The sequences for Cape molerat $\mathrm{CRF}_{1}$ and $\mathrm{CRF}_{2}$ are not yet known. Total CRF receptor binding was detected by incubating sections at room temperature for 120 minutes in $\left[{ }^{125} \mathrm{I}-\mathrm{Tyr}^{0}\right]$ sauvagine, a ligand that binds to both $\mathrm{CRF}_{1}$ and $\mathrm{CRF}_{2}$ with high affinity (Grigoriadis et al., 1996; Primus et al., 1997), in Tris-HCl buffer ( $\mathrm{pH}$ 7.4) containing $10 \mathrm{mM} \mathrm{MgCl}_{2}, 0.1 \%$ bovine serum albumin (Sigma-Aldrich) and $0.05 \%$ bacitracin (Sigma-Aldrich). $\mathrm{CRF}_{1}$ binding was detected by incubating sections in $\left[{ }^{125} \mathrm{I}_{-\mathrm{Tyr}}{ }^{0}\right]$ sauvagine in the presence of $\mathrm{a}$ selective $\mathrm{CRF}_{2}$ antagonist (Rivier et al., 2002; Hoare et al., 2005), $1 \mu \mathrm{M}$ nonradioactive astressin-2B (cyclo(31-34)[D-Phe ${ }^{11}, \mathrm{His}^{12}, \mathrm{C}(\alpha) \mathrm{MeLeu}^{13}, 39, \mathrm{Nle}^{17}$, $\mathrm{Glu}^{31}$, Lys ${ }^{34}$ Ac-Svg(6-40) trifluoroacetate salt; SigmaAldrich). $\mathrm{CRF}_{2}$ binding was detected by incubating sections with $\left[{ }^{125} \mathrm{I}-\mathrm{Tyr}^{0}\right]$ sauvagine in the presence of $1 \mu \mathrm{M}$ nonradioactive CP-154,526 (butyl-[2,5-dimethyl-7-(2,4,6trimethylphenyl) - 7H-pyrrolo[2,3-d]-pyrimidin-4-yl]-ethylamine; kindly provided by Dr L.J. Young, Center for Behavioral Neuroscience, Emory University, Atlanta, GA), a selective $\mathrm{CRF}_{1}$ antagonist (Schulz et al., 1996), as previously described (Lim et al., 2005). Unbound ligand was removed by three 5-minute washes in cold Tris- $\mathrm{HCl}$ buffer ( $\mathrm{pH}$ 7.4) containing $10 \mathrm{mM} \mathrm{MgCl}_{2}$, followed by a quick rinse in cold, deionized $\mathrm{H}_{2} \mathrm{O}$. Sections were finally dried under a stream of cold air prior to exposure to BioMax MR film (Kodak, Rochester, NY) along with ${ }^{125}$ I autoradiographic microscale standards (GE Healthcare, Bucks, United Kingdom) for 5 days. Sections from the two species were processed simultaneously. In an adjacent series of sections, it was found that competition of the

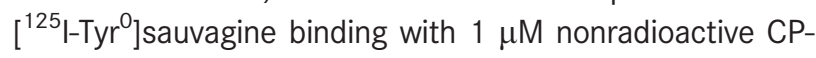
154,526 plus $1 \mu \mathrm{M}$ nonradioactive astressin-2B resulted in elimination of autoradiographic signals at all sites. After film development, sections were Nissl stained $(0.5 \%$ cresyl violet acetate), dehydrated, and coverslipped for microscopic examination. 
TABLE 1.

Primary Antibodies Used in This Study

\begin{tabular}{|c|c|c|c|c|}
\hline Target & Immunogen & $\begin{array}{l}\text { Host species and } \\
\text { antibody type }\end{array}$ & Source and RRID & Dilution used \\
\hline $\begin{array}{l}\text { Corticotropin-releasing } \\
\text { factor }\end{array}$ & $\begin{array}{l}\text { Synthetic human/rat CRF } \\
\text { peptide conjugated to } \\
\text { keyhole limpet hemocyanin }\end{array}$ & Rabbit polyclonal & $\begin{array}{l}\text { Peninsula Labs (Bachem Group) } \\
\quad \text { San Carlos, CA; T-4037, AB_2314240 }\end{array}$ & $1: 10,000$ \\
\hline Urocortin 3 & $\begin{array}{l}\text { Synthetic human Ucn } 3 \\
\text { peptide conjugated to } \\
\text { human } \alpha \text {-globulins with } \\
\text { bisdiazotized benzidine }\end{array}$ & Rabbit polyclonal & $\begin{array}{l}\text { Dr Wylie Vale, The Salk Institute } \\
\text { La Jolla, CA; PBL No. } 6570, \text { AB_2315528 }\end{array}$ & $1: 5,000$ \\
\hline
\end{tabular}

TABLE 2.

Alignment of Amino Acid Sequences for CRF and Ucn 3 in Various Mammalian Species ${ }^{1}$

\begin{tabular}{ll}
\hline Peptide & \\
\hline CRF & Sequence \\
Naked mole-rat & \\
Rat/human & SE EPPISLDLTFHLLREVLEMARAEQLAQQAHNNRKLM EII \\
Prairie vole & SE EPPISLDLTFHLLREVLEMARAEQLAQQAHSNRKLMEII \\
Sheep & SE EPPISLDLTFHLLREVLEMARAEQLAQQAHSNRKLMEII \\
Ucn 3 & SQEPPISLDLTFHLLREVLEMTIKADQLAQQAHSNRKL LDIA \\
Naked mole-rat & \\
Rat & FTLSLDVPTDIMNI LFNIARAKD SRARAAVNAQLMAQI \\
Human & FTLSLDVPTNIMNI LFNIDKAKINLRAKAAANAQLMAQI \\
Prairie vole & FTLSLDVPTNIMNLLFNIAKAKNLRAQAAANAHLMAQI \\
Sheep & FTLSLDVPTNIMNI LFNIDKAKNLRAKAAANAQLMAQI \\
\hline
\end{tabular}

${ }^{1}$ Variable sites across these species are shaded.

\section{Immunohistochemistry for CRF and Ucn 3}

The primary antisera used in this study (Table 1) were rabbit anti-CRF (T-4037, RRID AB_2314240; Peninsula Labs [Bachem Group], San Carlos, CA) and rabbit anti-Ucn 3 (PBL 6570, RRID AB_2315528; Dr Wylie Vale, The Salk Institute, La Jolla, CA). The polyclonal rabbit anti-CRF was raised against synthetic human/rat CRF conjugated to keyhole limpet hemocyanin. This antiserum has been used and characterized extensively (Hahn et al., 2003; Goodson et al., 2004; Tagliaferro and Morales, 2008; Biag et al., 2012). Dot blot analysis indicates that it binds to human or rat CRF, but not to rat Ucn 1, mouse Ucn 2, or human Ucn 3 (Tagliaferro and Morales, 2008). The antigen used to produce the Ucn 3 antiserum was synthetic human Ucn 3 conjugated to human $\alpha$-globulins with bisdiazotized benzidine (Li et al., 2002). This antiserum has also been used and characterized extensively (Li et al., 2002, 2003; Wittmann et al., 2009; Chen et al., 2011). Competition studies show that its immunoreactivity is abolished by low micromolar concentrations of synthetic mouse or human Ucn 3 but unaffected by Ucn 1, Ucn 2, or urotensin 1 in the high micromolar range (Li et al., 2002). Pretreatment of this antibody with CRF has been reported to have no effect on its immunoreactivity within the central nervous system, other than in the external zone of the median eminence (Li et al., 2002); consequently, although the median eminence was not investigated in the present study, the antiserum was routinely exposed to synthetic human/rat CRF ( $\mathrm{H}-2435$, $1 \mu \mathrm{g} / \mathrm{ml}$; Bachem, Ltd., St. Helens, United Kingdom) before use. The distributions of CRF and Ucn 3 immunoreactivity in the present study do not differ qualitatively from those reported for other mammals (see Discussion). Table 2 shows high similarity in the amino acid sequences for CRF in naked mole-rats (XP_004842173.1), rats (NP_112281.1), humans (NP_000747.1), prairie voles (XP_005361953.1), and sheep (XP_004011760.1) and for Ucn 3 in naked molerats (XM_004905981.1), rats (NP_001073677.1), humans (AAK67317.1), prairie voles (XP_005354964.1), and sheep (XP_004014362.1). The sequences for Cape mole-rat CRF and Ucn 3 are not yet known.

Immunohistochemistry was carried out according to methods previously described (Oosthuizen et al., 2008). Six sequential series of coronal sections $(25 \mu \mathrm{m})$ were produced with a cryostat. Two of the series were processed to visualize immunoreactivity for CRF and Ucn 3. The sections were pretreated with $0.5 \%$ Triton- $\mathrm{X} 100$ (BDH Chemical Company, Poole, United Kingdom). Endogenous peroxidase was suppressed by using $0.02 \%$ $\mathrm{H}_{2} \mathrm{O}_{2}$. The sections were washed in PBS, incubated in 
$2 \%$ normal donkey serum for 1 hour, and then exposed to rabbit anti-CRF $(1: 10,000)$ or rabbit anti-Ucn 3 $(1: 5,000)$ for 48 hours at $4^{\circ} \mathrm{C}$. After being washed in PBS again, the sections were incubated in biotin-SPconjugated AffiniPure donkey anti-rabbit IgG antiserum for 2 hours (1:1,000; Stratech, Newmarket, Suffolk, United Kingdom) at room temperature. After another wash in PBS, they were incubated in an avidin-biotin peroxidase complex (1:1,000; Elite Kit; Vector Laboratories, Peterborough, United Kingdom) for 2 hours at room temperature. After being transferred to Tris buffer (Trizma 7.6; Sigma-Aldrich), they were incubated in $0.05 \%$ diaminobenzidine with $0.15 \%$ ammonium nickel sulfate and $0.005 \% \mathrm{H}_{2} \mathrm{O}_{2}$ to visualize the immunoreactivity. All sections were processed concurrently.

Increasing dilutions of each of the primary antisera led to a commensurate attenuation of the immunoreactive signal. No immunoreactivity was observed when either the primary or the secondary antiserum was omitted or when the CRF or Ucn 3 antiserum was pretreated overnight with, respectively, synthetic human/ rat CRF $(\mathrm{H}-2435,1 \mu \mathrm{g} / \mathrm{ml}$; Bachem, Ltd.) or synthetic rat/mouse or human Ucn $3(\mathrm{H}-5634$ and $\mathrm{H}-5828,1$ $\mu \mathrm{g} / \mathrm{ml}$; Bachem, Ltd.).

For practical reasons, the mapping of putative endogenous ligands for $\mathrm{CRF}_{1}$ or $\mathrm{CRF}_{2}$ is limited to $\mathrm{CRF}$ and Ucn 3. Further research would be needed to ascertain the distributions of Ucn 1- or Ucn 2-ir processes; thus far, the latter have evaded detection in all species tested.

\section{Image analysis and quantification}

Autoradiographic films and histological sections were examined with a precision illuminator (Northern Light model R95; Interfocus Imaging, Cambridge, United Kingdom) and a Nikon Eclipse E600 microscope (Interfocus Imaging). Autoradiographs and photomicrographs were captured digitally with, respectively, a CoolSnap CF camera (Photometrics, Marlow, United Kingdom) and a Micro-Publisher 5.0 camera (Interfocus Imaging), both controlled by MCID Core software (InterFocus Imaging). Quantification of autoradiographic signals (MCID Core software) was carried out in anatomically matched sections, with areas of equal size for a given region; these areas fell within the borders of regions that were identified by the overlaying of images of film autoradiographs and corresponding Nissl-stained sections (Adobe Photoshop 7.0; Adobe Systems, Mountain View, CA). Signal intensity was determined by converting relative optical density values to disintegrations per minute (DPM)/mg of tissue equivalent using a set of ${ }^{125} \mathrm{I}$ microscale standards (GE Healthcare) exposed with the brain sections. Specific signal intensity values were established following subtraction of nonspecific binding values obtained from adjacent sections incubated concurrently in the presence of $1 \mu \mathrm{M}$ nonradioactive CP-154,526 and astressin-2B. Only values exceeding $2 \mathrm{SD}$ from the mean nonspecific binding values were considered detectable; regions within the forebrain that displayed autoradiographic signals satisfying this criterion in at least one of the two species were quantified and compared. In addition to the cingulate cortex, the somatosensory cortex was selected as a neocortical area for analysis. For a given area of interest, bilateral measurements of specific signal intensity were obtained from two to four sections per animal. These values were used to calculate the mean value for each animal and the species mean $\pm \mathrm{SE}$ values. Interspecies comparisons were carried out by using Student's $t$-test. $P=0.05$ was considered statistically significant. To prepare the images for publication, the original Tif files were imported into Adobe Photoshop; this application was used to make minor adjustments to contrast and brightness and to crop the images, compose them into plates, and label them.

\section{RESULTS \\ $\mathrm{CRF}_{1}$ binding in the telencephalon of naked mole-rats and Cape mole-rats}

$\mathrm{CRF}_{1}$ binding signals in the telencephalon differ in distribution or intensity between naked and Cape molerats (Figs. 1-8, Table 3). Where differences between naked and Cape mole-rats were found in the presence or intensity of the $\mathrm{CRF}_{1}$ binding signal, the level was greater in naked mole-rats in all but two of the identified sites (Table 3 ). In Cape mole-rats, there is a high level of $\mathrm{CRF}_{1}$ binding in the rostral shell of the nucleus accumbens; this is significantly greater than the moderate level found at this site in naked mole-rats (Figs. $1 A, B, 2 A, B$, Table 3). Within the cerebral cortex, both species exhibit moderate or intense levels of $\mathrm{CRF}_{1}$ binding; the binding signal is particularly strong throughout the cingulate cortex (Figs. 1A,B-4A,B, Table 3). In the somatosensory cortex, piriform cortex and claustrum, the level of binding is greater in naked mole-rats (Figs. 1A,B-6A,B, Table 3). In the septal nuclei, neither species displays binding signals that exceed the background level (Figs, 3A,B, 4A,B, Table 3).

Within the extended amygdala (Figs. 5A,B-8A,B), encompassing the amygdaloid nuclei, the amygdalostriatal transition area, and the bed nucleus of the stria terminalis (BNST), the highest levels of $\mathrm{CRF}_{1}$ binding in the two species are found in the lateral and basolateral nuclei; the intense level observed in the basolateral nucleus in naked mole-rats exceeds the high level 


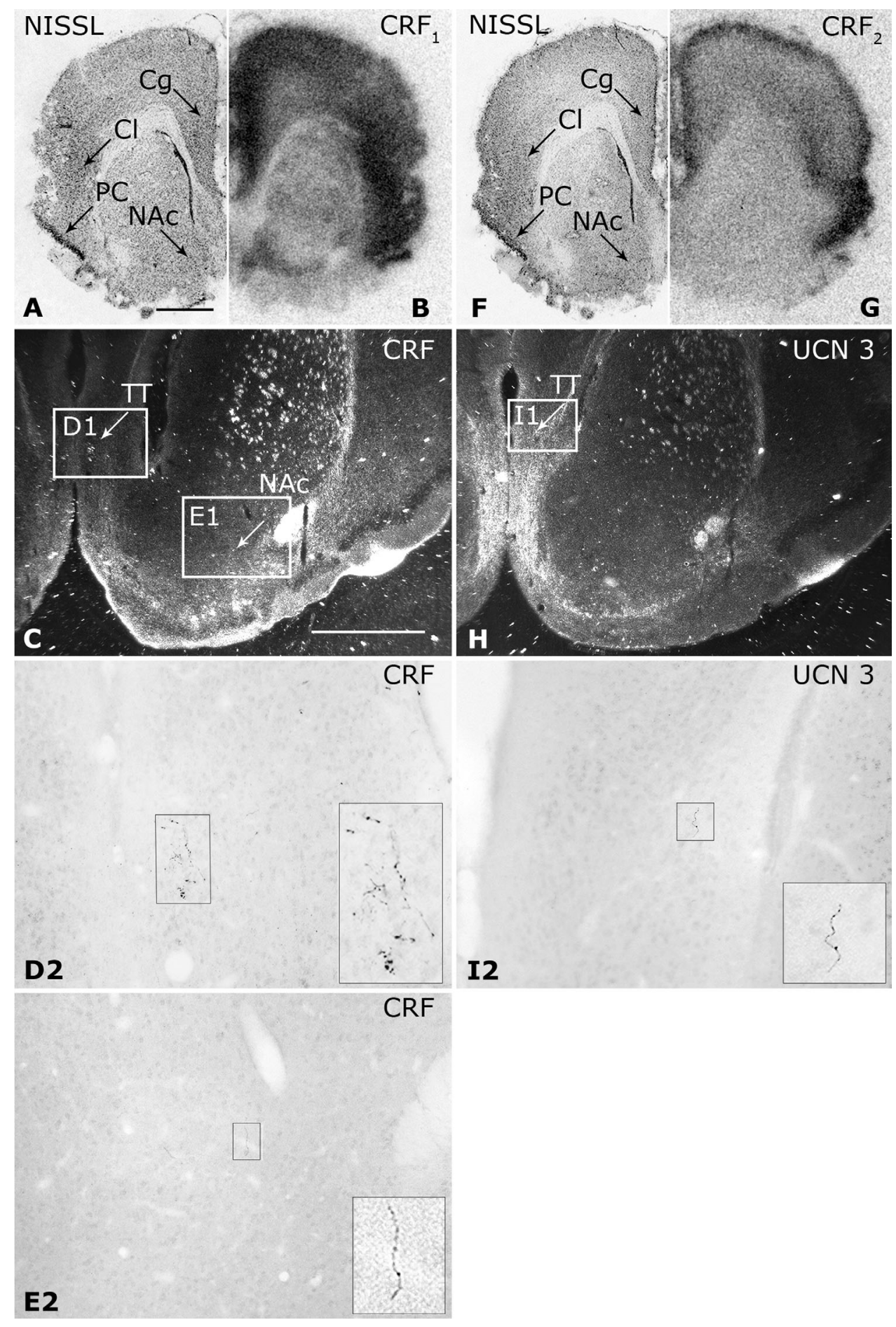

Figure 1. Naked mole-rat. Representative photomicrographs of Nissl-stained coronal hemisections $(\mathbf{A}, \mathbf{F})$ and the corresponding film autoradiographs (B,G, left/right reversed to facilitate comparisons) showing $\mathrm{CRF}_{1}$ binding $(\mathrm{B})$ and $\mathrm{CRF}_{2}$ binding $(\mathrm{G})$ at the rostrocaudal midrostrocaudal level of the rostral nucleus accumbens in a male naked mole-rat. Representative darkfield and brightfield photomicrographs showing CRF-ir processes (C,D1/2,E1/2) and Ucn 3-ir processes $(\mathbf{H}, \mathbf{I 1 / 2})$ at the rostrocaudal level of the rostral nucleus accumbens in a male naked mole-rat. Boxed regions containing CRF-ir processes (D1,E1) or Ucn 3-ir processes (I1) are shown at higher magnification (D2,E2,I2, each of which contains a further magnification from a smaller to a larger boxed region). Cg, cingulate cortex; NAc, nucleus accumbens; PC, piriform cortex; TT, taenia tecta. Scale bars $=1 \mathrm{~mm}$ in $\mathrm{A}$ (applies to A,B,F,G); $1 \mathrm{~mm}$ in C (applies to C,H). 


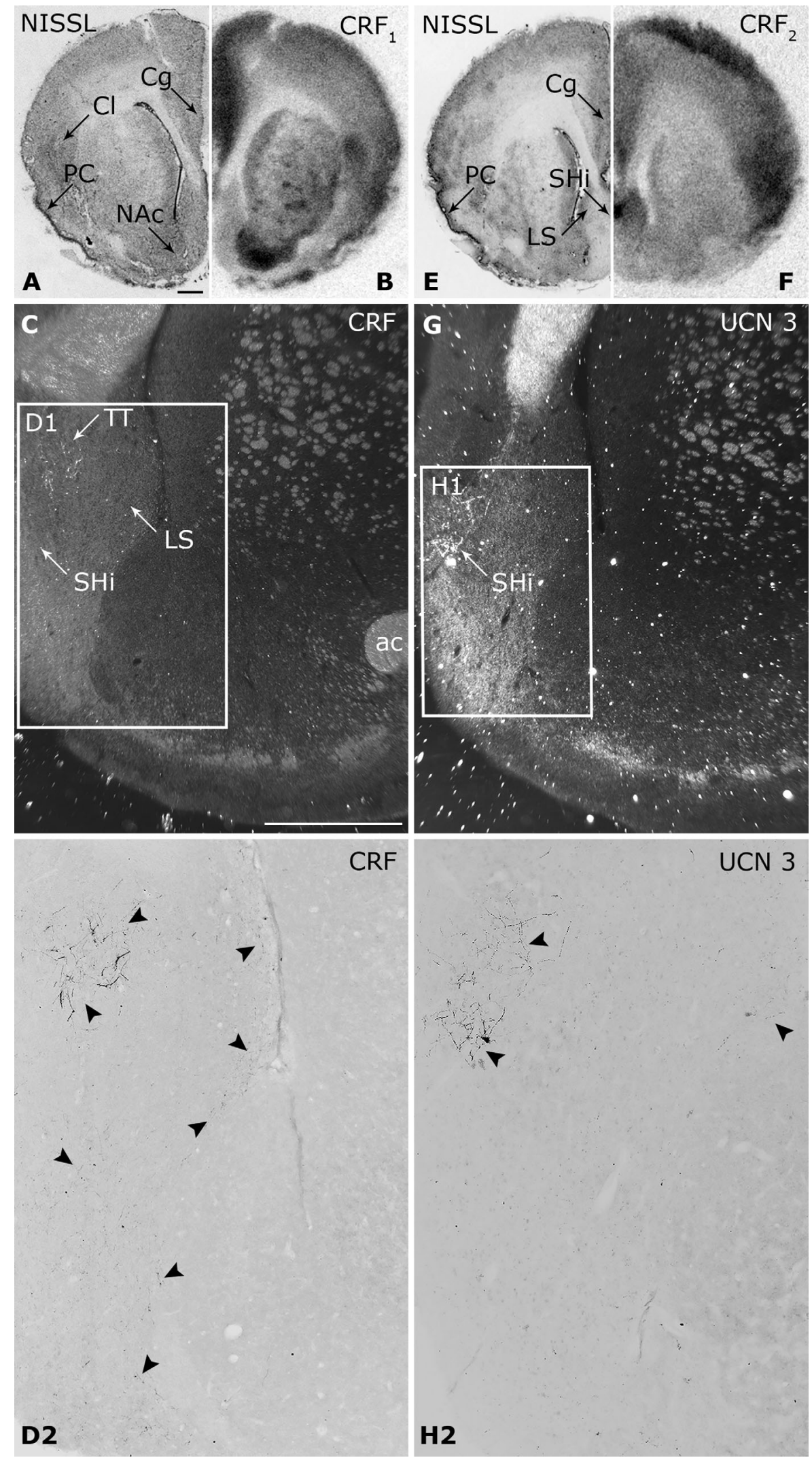

Figure 2. Cape mole-rat. Representative photomicrographs of Nissl-stained coronal hemisections $(\mathbf{A}, \mathbf{E})$ and the corresponding film autoradiographs (B,F, left/right reversed to facilitate comparisons) showing $\mathrm{CRF}_{1}$ binding $(\mathrm{B})$ and $\mathrm{CRF}_{2}$ binding $(\mathrm{F})$ at the rostrocaudal level of the rostral nucleus accumbens in a male Cape mole-rat. Representative darkfield and brightfield photomicrographs showing CRF-ir processes (C,D1/2) and Ucn 3-ir processes $(\mathbf{G}, \mathbf{H 1}$ 1/2) at the rostrocaudal level of the rostral nucleus accumbens in a male Cape mole-rat. Boxed regions containing CRF-ir processes (D1) or Ucn 3-ir processes (H1) are shown at higher magnification (D2,H2). Arrowheads indicate selected immunoreactive processes. ac, anterior commissure; $\mathrm{Cg}$, cingulate cortex; Cl, claustrum; LS, lateral septal nuclei; NAc, nucleus accumbens; PC, piriform cortex; Shi, septohippocampal nucleus; TT, taenia tecta. Scale bars $=1 \mathrm{~mm}$ in $\mathrm{A}$ (applies to A,B,E,F); $1 \mathrm{~mm}$ in $\mathrm{C}$ (applies to $\mathrm{C}, \mathrm{G}$ ). 


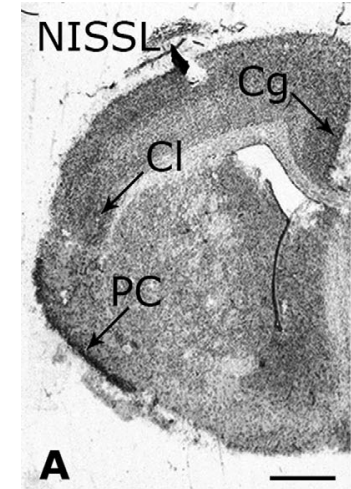

A

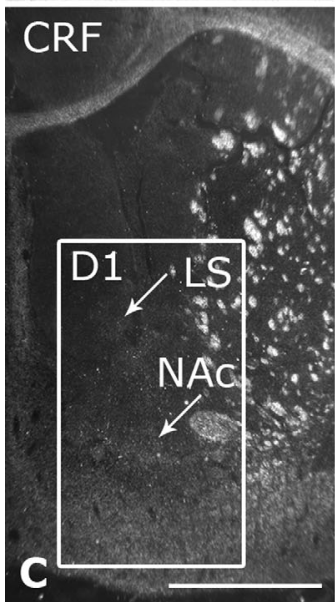

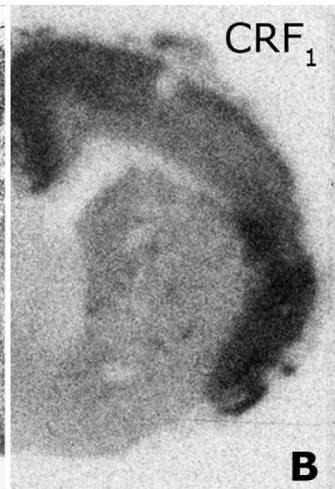

B $\mathbf{E}$

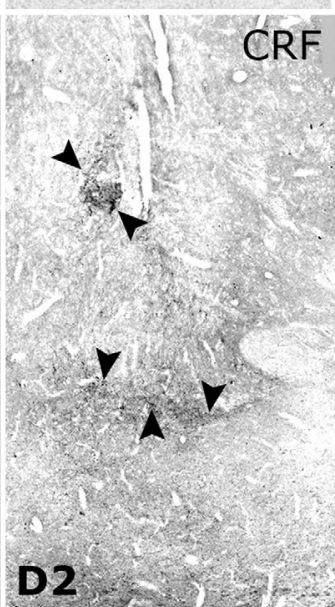

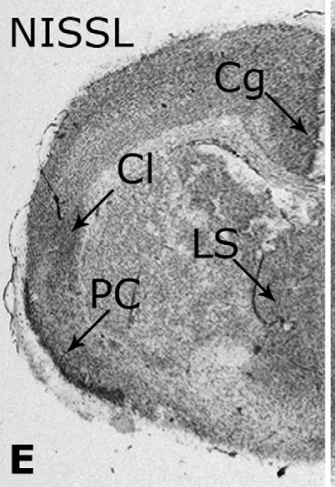
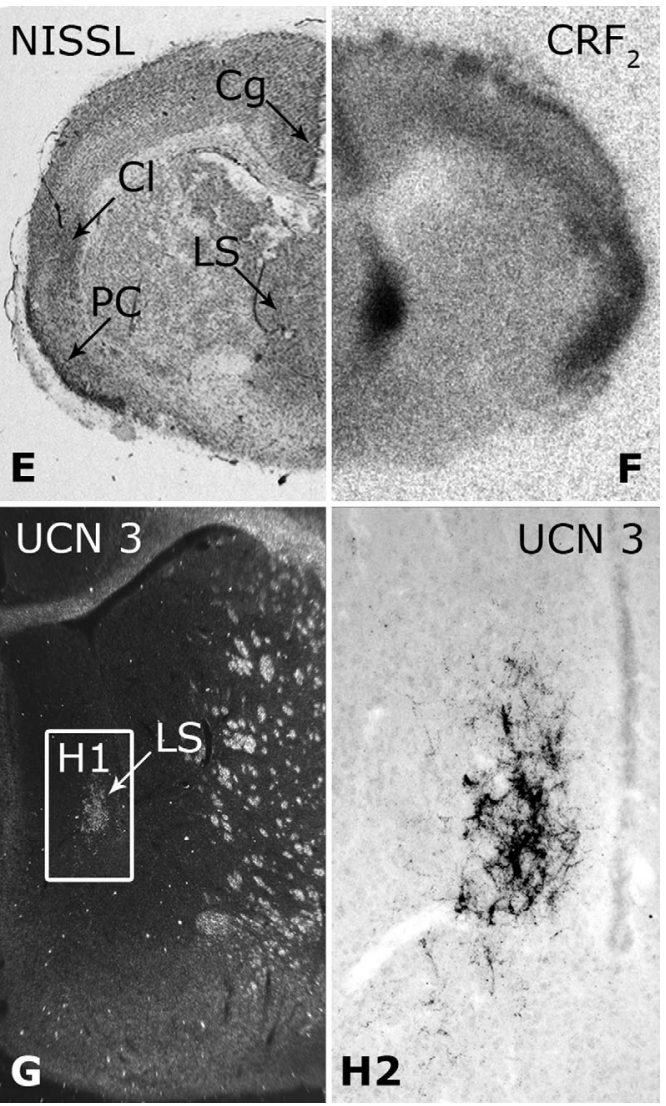

Figure 3. Naked mole-rat. Representative photomicrographs of Nissl-stained coronal hemisections $(\mathbf{A}, \mathbf{E})$ and the corresponding film autoradiographs (B,F, left/right reversed to facilitate comparisons) showing $\mathrm{CRF}_{1}$ binding $(\mathrm{B})$ and $\mathrm{CRF}_{2}$ binding $(\mathrm{F})$ at the midrostrocaudal level of the septal nuclei in a male naked mole-rat. Representative darkfield and brightfield photomicrographs showing CRF-ir processes (C,D1/ 2) and Ucn 3-ir processes $(\mathbf{G}, \mathrm{H} 1 / 2)$ at the midrostrocaudal level of the septal nuclei in a male naked mole-rat. Boxed regions containing CRF-ir processes (D1) or Ucn 3-ir processes (H1) are shown at higher magnification (D2,H2). Arrowheads indicate selected immunoreactive processes. $\mathrm{Cg}$, cingulate cortex; LS, lateral septal nuclei; NAc, nucleus accumbens; PC, piriform cortex. Scale bars $=1 \mathrm{~mm}$ in A (applies to $A, B, E, F) ; 1 \mathrm{~mm}$ in $C$ (applies to $C, G$ ).

found at this site in Cape mole-rats (Table 3). The low levels in the central nucleus and the moderate levels in the medial nucleus and amygdalostriatal transition area are similar in both species (Table 3); this is also the case for the low levels of binding in the BNST (Table 3). Within the hippocampal formation, which is proportionally very large in naked mole-rats, both species display $\mathrm{CRF}_{1}$ binding at a moderate level in the $\mathrm{CA} 1$ subfield and at a low level in the CA2 subfield (Figs. 7A,B, 8A,B, Table 3). In contrast, in the CA3 subfield, there is a high level of $\mathrm{CRF}_{1}$ binding in naked mole-rats but only a low level in Cape mole-rats (Table 3). In the dentate gyrus, the moderate level of binding in naked mole-rats exceeds that in Cape mole-rats (Table 3); the binding signals are located predominantly in the molecular layer in the former species and in the polymorph layer in the latter species. In the medial habenular nucleus, $\mathrm{CRF}_{1}$ binding is present at a moderate level in Cape molerats but is not detected in naked mole-rats (Table 3).

\section{$\mathrm{CRF}_{2}$ binding in the telencephalon of naked mole-rats and Cape mole-rats}

Where differences between naked and Cape molerats were found in the presence or intensity of the $\mathrm{CRF}_{2}$ binding signal, the level was greater in Cape mole-rats in all but three of the identified sites (Table 3). In the nucleus accumbens, there is no detectable $\mathrm{CRF}_{2}$ binding in either species (Figs. 1F,G, 2E,F, Table 3). In the cerebral cortex, both species exhibit only low or moderate levels of $\mathrm{CRF}_{2}$ binding, the highest level being found in the piriform cortex; within the somatosensory region, the level is greater in Cape mole-rats than naked mole-rats (Figs. 1F,G, 2E,F-6E,F, Table 3). In the claustrum, $\mathrm{CRF}_{2}$ binding is present at a moderate level in naked mole-rats but is absent in Cape molerats (Figs. 1F,G, 3E,F, Table 3). In contrast, in the septohippocampal nucleus, it is seen at a high level in Cape mole-rats but is not detected in naked mole-rats (Figs. 1F,G, 2E,F, Table 3). The intense binding present 

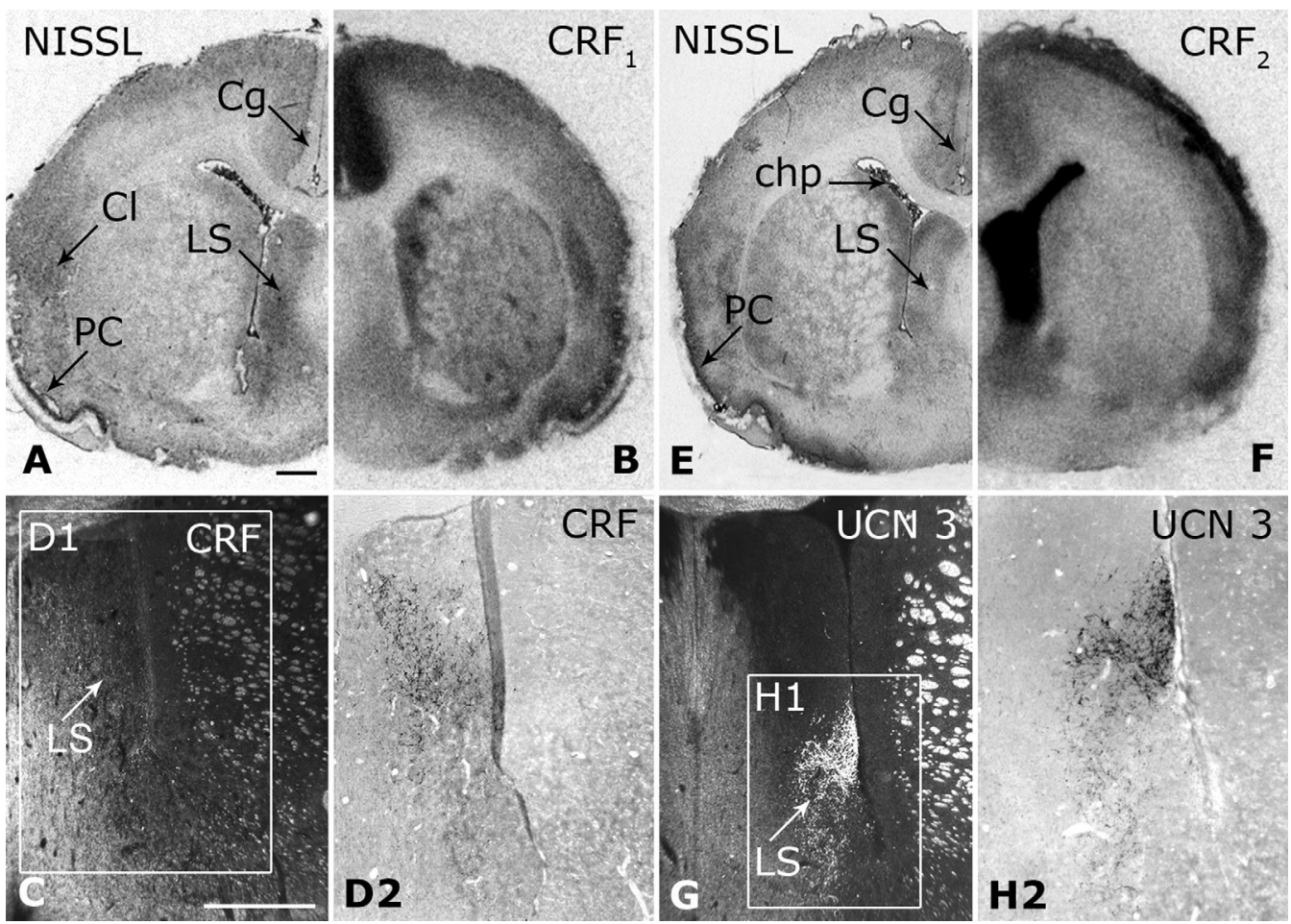

Figure 4. Cape mole-rat. Representative photomicrographs of Nissl-stained coronal hemisections $(\mathbf{A}, \mathbf{E})$ and the corresponding film autoradiographs (B,F, left/right reversed to facilitate comparisons) showing $\mathrm{CRF}_{1}$ binding $(\mathrm{B})$ and $\mathrm{CRF}_{2}$ binding $(\mathrm{F})$ at the midrostrocaudal level of the septal nuclei in a male Cape mole-rat. Representative darkfield and brightfield photomicrographs showing CRF-ir processes (C,D1/ 2) and Ucn 3-ir processes $(\mathbf{G}, \mathbf{H 1}$ /2) at the midrostrocaudal level of the septal nuclei in a male Cape mole-rat. Boxed regions containing CRF-ir processes (D1) or Ucn 3-ir processes (H1) are shown at higher magnification (D2,H2). Cg, cingulate cortex; chp, choroid plexus; $\mathrm{Cl}$, claustrum; LS, lateral septal nuclei; PC, piriform cortex. Scale bars $=1 \mathrm{~mm}$ in A (applies to A,B,E,F); $1 \mathrm{~mm}$ in $\mathrm{C}$ (applies to C,G).

throughout the dorsal, intermediate, and ventral subdivisions of the lateral septum in Cape mole-rats exceeds the moderate level found in the intermediate and ventral subdivisions in naked mole-rats (Figs. 3E,F, 4E,F, Table 3). In both species, the choroid plexus contains the highest level of $\mathrm{CRF}_{2}$ binding detected in this study (Figs. 4E,F-8E,F, Table 3).

Within the extended amygdala (Figs. 5E,F-8E,F), the amygdaloid nuclei are characterized by weak to moderate $\mathrm{CRF}_{2}$ binding in both species; the highest level in each species is found in the lateral nucleus (Table 3). The level in the basolateral nucleus in naked mole-rats is greater than that in Cape mole-rats; the low levels in the central and medial nuclei are similar in both species (Table 3). The intense level found in the amygdalostriatal transition area in Cape mole-rats greatly exceeds the low level detected at this site in naked mole-rats (Table 3). Both species display a low level of $\mathrm{CRF}_{2}$ binding in the lateral division of the BNST; at this site, the level is greater in Cape mole-rats than in naked molerats (Table 3). Within the hippocampal formation of both species (Figs. 7E,F, 8E,F), only the dentate gyrus exhibits $\mathrm{CRF}_{2}$ binding; the binding signals, which are associated with the molecular layer, are at a distinctly greater level in naked mole-rats than in Cape mole-rats (Table 3). The medial habenular nucleus displays an intense level of $\mathrm{CRF}_{2}$ binding in Cape mole-rats, which exceeds that found in naked mole-rats (Table 3 ).

\section{CRF immunoreactivity in the telencephalon of naked mole-rats and Cape mole-rats}

CRF-immunoreactive (-ir) processes within the rostral nucleus accumbens are extremely sparse in naked mole-rats and are not detected in Cape mole-rats (Figs. $1 \mathrm{C}, \mathrm{E} 1 / 2,2 \mathrm{C})$. At this rostral level in naked mole-rats (Fig. 1C,D1/2), CRF-ir processes are found in the region of the taenia tecta at a very low density. At the latter site, Cape mole-rats display a slightly greater density of these processes (Fig. 2C,D1/2); in this species, diffuse CRF-ir processes are also found ventral and lateral to this site in the septohippocampal and rostral lateral septal nuclei (Fig. 2C,D1/2). In both species, CRFir processes and cell bodies are seen sporadically within the cerebral cortex (not shown). At the midrostrocaudal level of the septal nuclei (Fig. 3C,D1/2), 


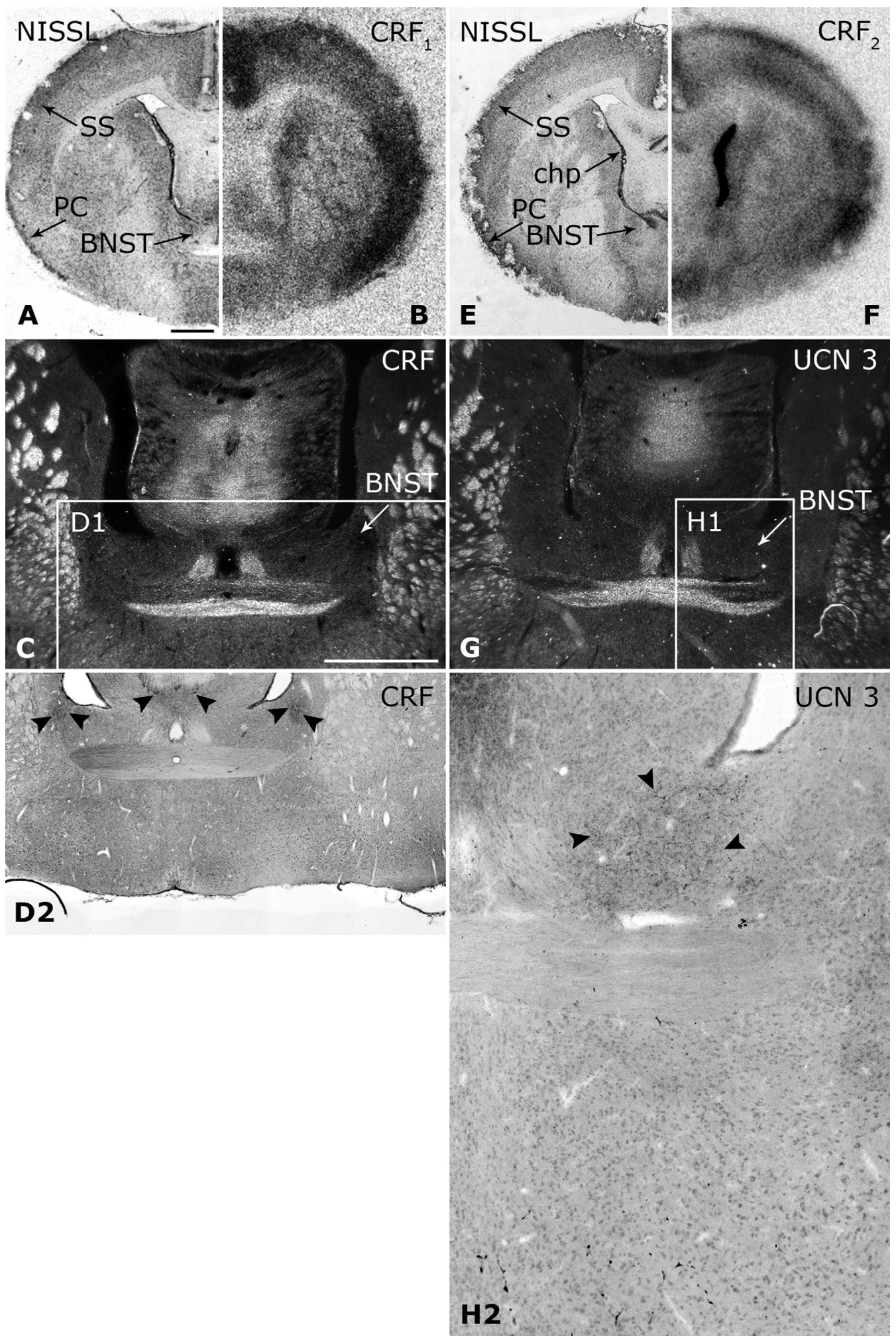

Figure 5. Naked mole-rat. Representative photomicrographs of Nissl-stained coronal hemisections $(\mathbf{A}, \mathbf{E})$ and the corresponding film autoradiographs (B,F, left/right reversed to facilitate comparisons) showing $\mathrm{CRF}_{1}$ binding $(\mathrm{B})$ and $\mathrm{CRF}_{2}$ binding $(\mathrm{F})$ at the rostrocaudal level of the fused anterior commissure in a male naked mole-rat. Representative darkfield and brightfield photomicrographs showing CRF-ir processes (C,D1/2) and Ucn 3-ir processes $(\mathbf{G}, \mathbf{H} 1 / 2)$ at the rostrocaudal level of the fused anterior commissure in a male naked mole-rat. Boxed regions containing CRF-ir processes (D1) or Ucn 3-ir processes (H1) are shown at higher magnification (D2,H2). Arrowheads indicate selected immunoreactive processes. BNST, bed nucleus of the stria terminalis; chp, choroid plexus; PC, piriform cortex; SS, somatosensory cortex. Scale bars $=1 \mathrm{~mm}$ in $\mathrm{A}$ (applies to A,B,E,F); $1 \mathrm{~mm}$ in C (applies to C,G). 

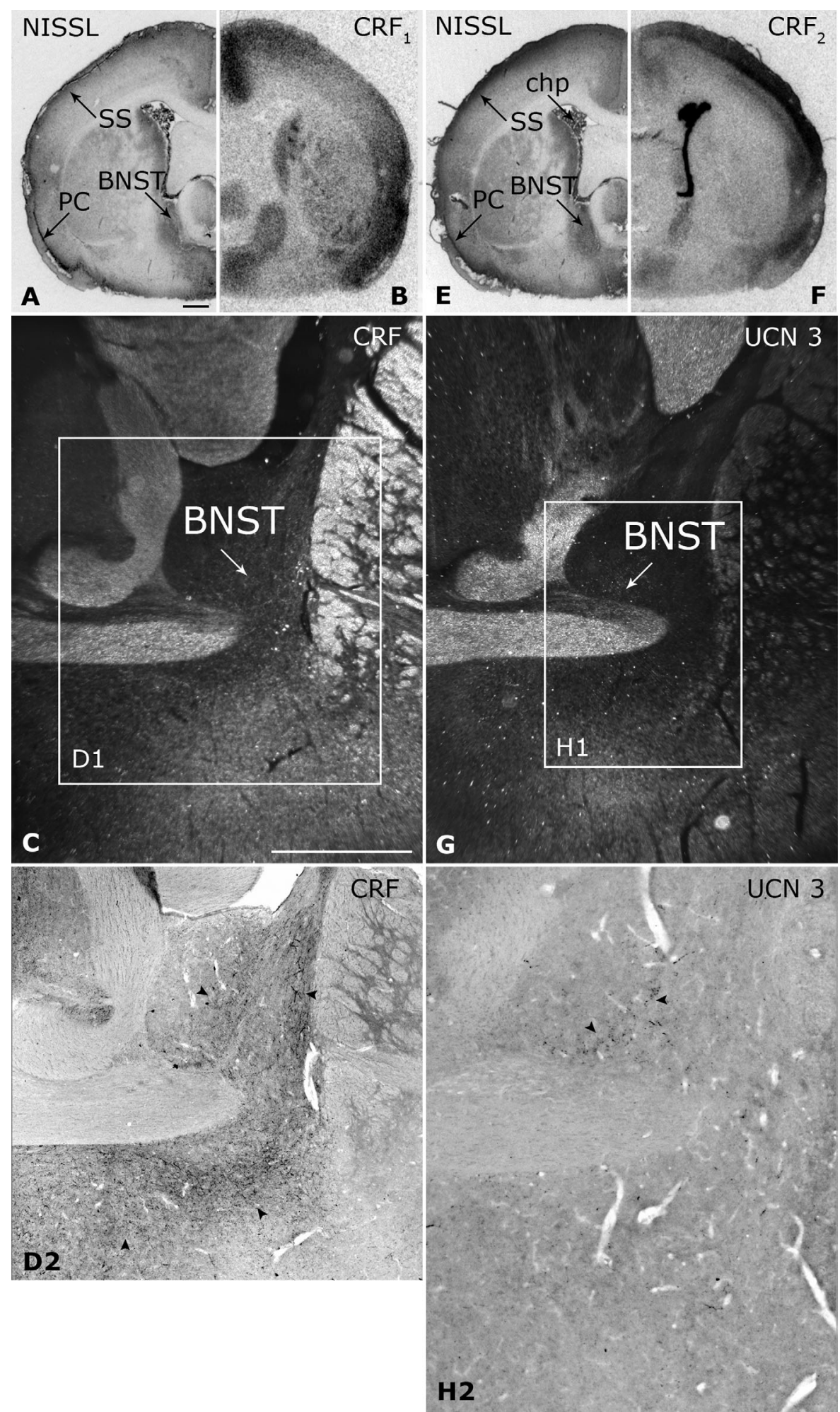

Figure 6. Cape mole-rat. Representative photomicrographs of Nissl-stained coronal hemisections $(\mathbf{A}, \mathbf{E})$ and the corresponding film autoradiographs (B,F, left/right reversed to facilitate comparisons) showing $\mathrm{CRF}_{1}$ binding $(\mathrm{B})$ and $\mathrm{CRF}_{2}$ binding $(\mathrm{F})$ at the rostrocaudal level of the fused anterior commissure in a male Cape mole-rat. Representative darkfield and brightfield photomicrographs showing CRF-ir processes (C,D1/2) and Ucn 3-ir processes $(\mathbf{G}, \mathbf{H} 1 / 2)$ at the rostrocaudal level of the fused anterior commissure in a male Cape mole-rat. Boxed regions containing CRF-ir processes (D1) or Ucn 3-ir processes (H1) are shown at higher magnification (D2,H2). Arrowheads indicate selected immunoreactive processes. BNST, bed nucleus of the stria terminalis; chp, choroid plexus; PC, piriform cortex; SS, somatosensory cortex. Scale bars $=1 \mathrm{~mm}$ in $A$ (applies to A,B,E,F); $1 \mathrm{~mm}$ in C (applies to C,G). 


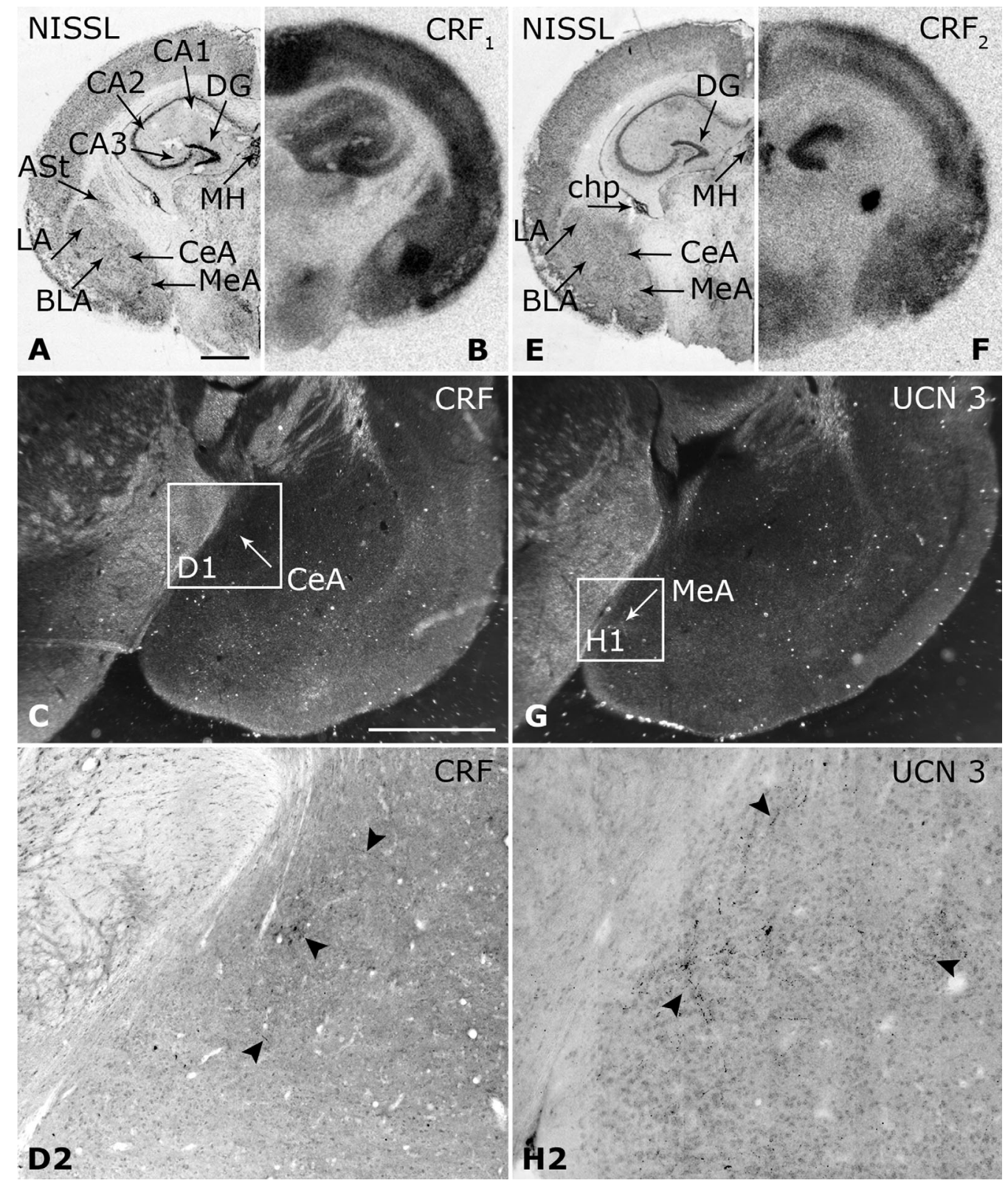

Figure 7. Naked mole-rat. Representative photomicrographs of Nissl-stained coronal hemisections $(\mathbf{A}, \mathbf{E})$ and the corresponding film autoradiographs (B,F, left/right reversed to facilitate comparisons) showing $\mathrm{CRF}_{1}$ binding $(\mathrm{B})$ and $\mathrm{CRF}_{2}$ binding $(\mathrm{F})$ at the midrostrocaudal level of the amygdaloid nuclei in a male naked mole-rat. Representative darkfield and brightfield photomicrographs showing CRF-ir processes $(C, D 1 / 2)$ and Ucn 3-ir processes $(G, H 1 / 2)$ at the midrostrocaudal level of the amygdaloid nuclei in a male naked mole-rat. Boxed regions containing CRF-ir processes (D1) or Ucn 3-ir processes (H1) are shown at higher magnification (D2,H2). Arrowheads indicate selected immunoreactive processes. ASt, amygdalostriatal transition area; BLA, basolateral amygdaloid nucleus; CA1, CA1 subfield of the hippocampus; CA2, CA2 subfield of the hippocampus; CA3, CA3 subfield of the hippocampus; CeA, central amygdaloid nucleus; chp, choroid plexus; DG, dentate gyrus; LA, lateral amygdaloid nucleus; MeA, medial amygdaloid nucleus; $\mathrm{MH}$, medial habenular nucleus. Scale bars $=1 \mathrm{~m}$ min A (applies to A,B,E,F); $1 \mathrm{~mm}$ in $\mathrm{C}$ (applies to $\mathrm{C}, \mathrm{G}$ ).

naked mole-rats display CRF-ir processes in the ventral lateral septal nucleus (in a dense plexus), in the caudal nucleus accumbens, and close to the ventral surface of the brain. At this rostrocaudal level in Cape mole-rats (Fig. 4C,D1/2), CRF-ir processes are found at a moderate density in the lateral septum, predominantly within its intermediate subdivision. In naked mole-rats at the rostrocaudal level of the fused anterior commissure (Fig. 5C,D1/2), CRF-ir processes are present at a low density immediately ventrolateral to the base of the lateral ventricle in the dorsal part of the lateral division of the BNST and in the dorsal median preoptic nucleus 


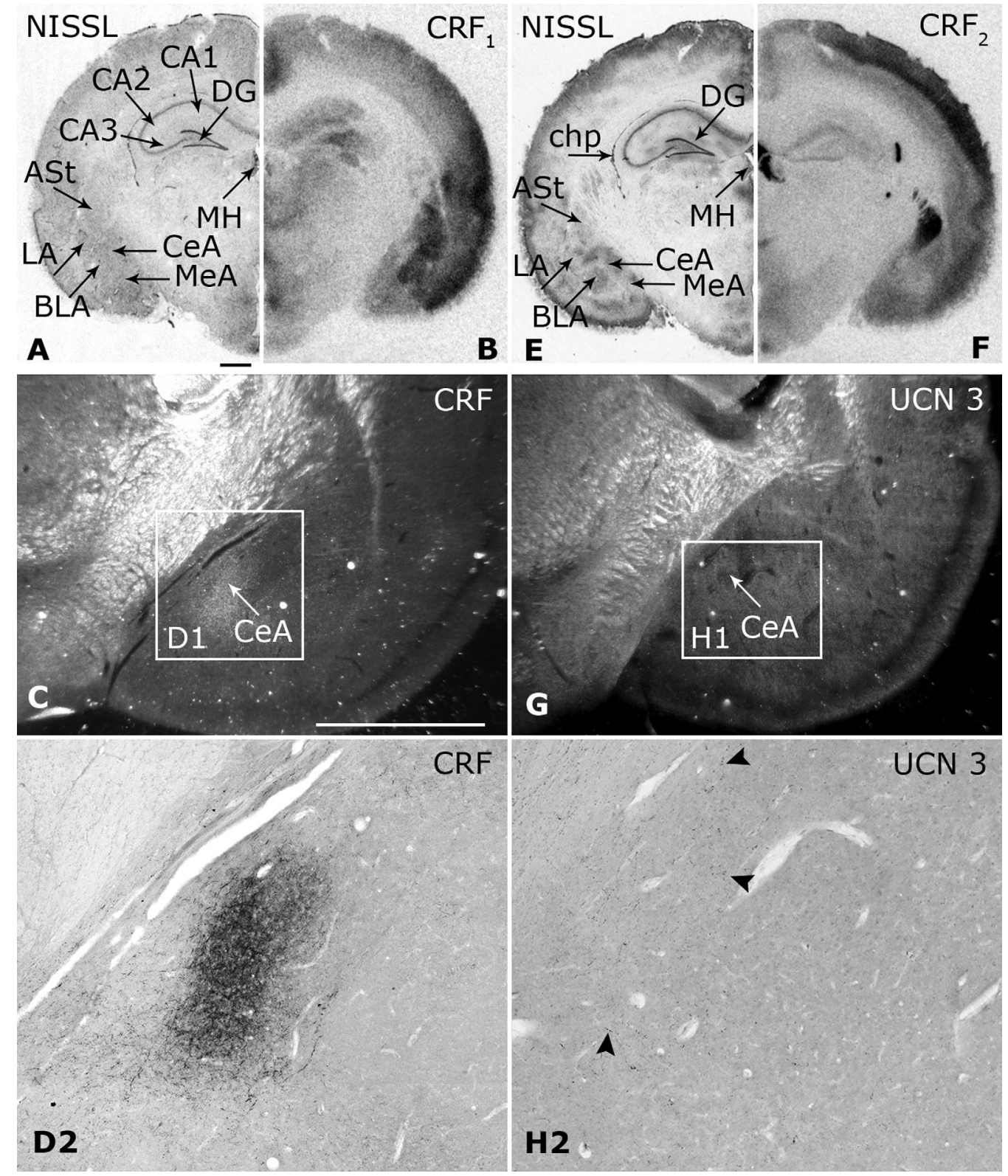

Figure 8. Cape mole-rat. Representative photomicrographs of Nissl-stained coronal hemisections (A,E) and the corresponding film autoradiographs (B,F, left/right reversed to facilitate comparisons) showing $\mathrm{CRF}_{1}$ binding $(\mathrm{B})$ and $\mathrm{CRF}_{2}$ binding $(\mathrm{F})$ at the midrostrocaudal level of the amygdaloid nuclei in a male Cape mole-rat. Representative darkfield and brightfield photomicrographs showing CRF-ir processes (C,D1/2) and Ucn 3-ir processes (G,H1/2) at the midrostrocaudal level of the amygdaloid nuclei in a male Cape mole-rat. Boxed regions containing CRF-ir processes (D1) or Ucn 3-ir processes (H1) are shown at higher magnification (D2,H2). Arrowheads indicate selected immunoreactive processes. ASt, amygdalostriatal transition area; BLA, basolateral amygdaloid nucleus; CA1, CA1 subfield of the hippocampus; CA2, CA2 subfield of the hippocampus; CA3, CA3 subfield of the hippocampus; CeA, central amygdaloid nucleus; chp, choroid plexus; DG, dentate gyrus; LA, lateral amygdaloid nucleus; MeA, medial amygdaloid nucleus; $\mathrm{MH}$, medial habenular nucleus. Scale bars $=1 \mathrm{~m}$ min A (applies to $A, B, E, F) ; 1 \mathrm{~mm}$ in $C$ (applies to $C, G$ ).

around the base of the triangular septal nucleus. At this rostrocaudal level in Cape mole-rats (Fig. 6C,D1/2), there is a high incidence of CRF-ir processes throughout the BNST, ventral, dorsal, and lateral to the anterior commissure. Within the amygdaloid nuclei, CRF-ir processes are detected in the central nucleus in both spe- cies: at a low density in naked mole-rats (Fig. 7C,D1/2) and in a highly dense plexus in Cape mole-rats (Fig. $8 \mathrm{C}, \mathrm{D} 1 / 2)$. In naked mole-rats, diffuse CRF-ir profiles are found in the CA1, CA2, and CA3 subfields of the hippocampus and in the molecular layer of the dentate gyrus; in contrast, in Cape mole-rats they are seen in 
TABLE 3.

$\mathrm{CRF}_{1}$ and $\mathrm{CRF}_{2}$ Binding, as Indicated by [ $\left.{ }^{125} \mathrm{I}-\mathrm{Tyr}^{0}\right]$ Sauvagine Binding in the Presence of, Respectively, a Nonradioactive $\mathrm{CRF}_{2}$ or $\mathrm{CRF}_{1}$ Antagonist (Mean $\pm \mathrm{SEM}$; dpm/mg Tissue Equivalent; $n=3-5$ ), at Telencephalic Sites in Male Nonreproductive Naked Mole-Rats and Male Cape Mole-Rats Outside the Breeding Season

\begin{tabular}{|c|c|c|c|c|}
\hline \multirow[b]{2}{*}{ Site } & \multicolumn{2}{|c|}{$\mathrm{CRFR}_{1}$} & \multicolumn{2}{|c|}{$\mathrm{CRFR}_{2}$} \\
\hline & Naked mole-rat & Cape mole-rat & Naked mole-rat & Cape mole-rat \\
\hline Nucleus accumbens rostral shell & $25,302 \pm 2,255^{1}$ & $41,301 \pm 4,296$ & ND & ND \\
\hline Cingulate cortex & $67,634 \pm 2,854$ & $64,364 \pm 8,965$ & $17,200 \pm 1,296$ & $11,547 \pm 1,647$ \\
\hline Piriform cortex & $66,820 \pm 5,937^{1}$ & $48,749 \pm 1,713$ & $33,760 \pm 3,546$ & $39,984 \pm 2,838$ \\
\hline Somatosensory cortex & $50,032 \pm 7,106^{1}$ & $27,355 \pm 2,948$ & $7,507 \pm 754^{2}$ & $20,204 \pm 2,169$ \\
\hline Hippocampal CA 1 subfield & $33,532 \pm 2,181$ & $22,274 \pm 5,061$ & ND & ND \\
\hline Hippocampal CA2 subfield & $6,942 \pm 642$ & $7,261 \pm 561$ & ND & ND \\
\hline Hippocampal CA3 subfield & $44,577 \pm 1,847^{2}$ & $10,977 \pm 999$ & ND & ND \\
\hline Dentate gyrus & $25,686 \pm 740^{2}$ & $13,178 \pm 1,981$ & $39,025 \pm 2,041^{2}$ & $7,516 \pm 414$ \\
\hline Claustrum & $63,437 \pm 2,582^{2}$ & $40,661 \pm 3,616$ & $16,479 \pm 2,163$ & ND \\
\hline Caudate putamen & $16,933 \pm 2,622$ & $21,715 \pm 4,373$ & $2,371 \pm 556$ & $1,703 \pm 31$ \\
\hline Septohippocampal nucleus & $N D^{3}$ & ND & ND & $35,519 \pm 3,303^{4}$ \\
\hline Lateral septal nuclei & ND & ND & $26,628 \pm 208^{1}$ & $66,931 \pm 9,055$ \\
\hline Choroid plexus & ND & ND & $75,937 \pm 4,326$ & $79,421 \pm 5,429$ \\
\hline Lateral amygdaloid nucleus & $49,025 \pm 4,839$ & $47,264 \pm 5,893$ & $24,648 \pm 2,763$ & $17,409 \pm 3,438$ \\
\hline Basolateral amygdaloid nucleus & $68,085 \pm 595^{2}$ & $45,697 \pm 3,160$ & $18,361 \pm 1,437^{2}$ & $7,528 \pm 392$ \\
\hline Central amygdaloid nucleus & $13,903 \pm 2,747$ & $14,631 \pm 2,573$ & $14,248 \pm 2,231$ & $12,273 \pm 1,737$ \\
\hline Medial amygdaloid nucleus & $22,649 \pm 1,756$ & $20,316 \pm 1,819$ & $13,431 \pm 2,167$ & $14,903 \pm 2,049$ \\
\hline Amygdalostriatal transition area & $34,395 \pm 2,513$ & $38,318 \pm 4,118$ & $9,672 \pm 1,138^{2}$ & $73,790 \pm 3,388$ \\
\hline Bed nucleus of the stria terminalis & $13,098 \pm 657$ & $12,816 \pm 237$ & $9,628 \pm 668^{2}$ & $15,608 \pm 707$ \\
\hline Medial habenular nucleus & ND & $21,001 \pm 1,581^{4}$ & $39,624 \pm 3,364^{2}$ & $75,566 \pm 4,581$ \\
\hline
\end{tabular}

${ }^{1} P<0.05$ differences at sites that display binding signals in both species.

${ }^{2} P<0.01$ differences at sites that display binding signals in both species. ${ }^{3} \mathrm{ND}$, not detected.

${ }^{4}$ Sites at which binding signals are present in only one of the species.

the CA1 subfield and in the polymorph layer of the dentate gyrus (not shown). Although the medial habenular nucleus lacks CRF-ir processes in both species, they are present in the adjacent paraventricular nucleus of the thalamus at a moderate density (not shown).

\section{Ucn 3 immunoreactivity in the forebrain of naked mole-rats and Cape mole-rats}

The most rostral Ucn 3-ir processes are found in isolation in the region of the taenia tecta in naked molerats (Fig. $1 \mathrm{H}, \mathrm{I1} / 2$ ) and in a moderately dense cluster in the septohippocampal nucleus in Cape mole-rats (Fig. $2 \mathrm{G}, \mathrm{H} 1 / 2$ ). Caudal to this, at the midrostrocaudal level of the septal nuclei, Ucn 3-ir processes are present in the ventral subdivisions of the lateral septum; they form a dense plexus in naked mole-rats (Fig. 3G,H1/2) and in Cape mole-rats (Fig. 4G,H1/2). In naked mole-rats at the rostrocaudal level of the fused anterior commissure (Fig. 5G,H1/2), Ucn 3-ir processes are present within the BNST at a moderate density dorsal to the commissure and at a greater density in the dorsal median preoptic nucleus around the base of the triangular septal nucleus. In Cape mole-rats, there is a lower density of these processes dorsal to the commissure (Fig. 6G,H1/ 2). Within the amygdaloid nuclei, Ucn 3-ir processes are detected at a low density in the medial nucleus in naked mole-rats (Fig. 7G,H1/2) and in the central nucleus in Cape mole-rats (Fig. 8G,H1/2). Within the hippocampus, faint, diffuse Ucn 3-ir profiles are seen in the CA1, CA2, and CA3 subfields in naked mole-rats but only in the CA1 subfield in Cape mole-rats (not shown). In both species, Ucn 3-ir processes are absent from the medial habenular nucleus but are present at an extremely low density in the adjacent paraventricular nucleus of the thalamus (not shown).

\section{DISCUSSION}

The peptides and receptors that constitute the CRFrelated networks are implicated in many aspects of social behavior in a wide range of species (Hostetler and Ryabinin, 2013). Species-typical differences in affiliative behavior have been shown to be associated with species differences in the distribution and intensity of $\mathrm{CRF}_{1}$ and $\mathrm{CRF}_{2}$ binding (Lim et al., 2005).

The present study quantifies and compares $\mathrm{CRF}_{1}$ and $\mathrm{CRF}_{2}$ binding in the telencephalon of species that display extreme differences in social behavior: eusocial naked mole-rats and solitary Cape mole-rats. The research was designed to identify species-specific rather than state-dependent distributions for the binding and for the neuronal processes that contain two of 
the endogenous ligands for these receptors, CRF and Ucn 3. Given the presence of putative estrogen, progesterone, and androgen response elements on the promoter regions of the genes for these receptors and the evidence that sex steroids affect their binding levels (Lim et al., 2005; Bangasser, 2013), this study was restricted to animals with low or undetectable levels of urinary and plasma testosterone: adult male mole-rats, which were either subordinate, hypogonadal naked mole-rats or Cape mole-rats captured during the nonreproductive season (Bennett and Jarvis, 1988; Faulkes and Abbott, 1991; Zhou et al., 2013). In the following discussion, comparisons between the present findings and those obtained in studies of other mammals focus on the males of the species wherever possible. Descriptions of the level of binding or density of immunoreactive processes in the studies cited reflect the terms used in those studies and/or the reported levels relative to the observed range. Speculation about the distribution of cell bodies immunoreactive for CFR or Ucn 3 has been omitted because research on other species has indicated that the evidence is unreliable without intracerebroventricular colchicine treatment. We recognize that the current study has not addressed the possible roles of processes containing the other endogenous ligands for $\mathrm{CRF}_{1}$ or $\mathrm{CRF}_{2}$ : Ucn 1 and Ucn 2. The potential significance of Ucn 1 is discussed with reference to findings obtained in other species. Ucn 2 is discussed only with reference to its mRNA expression; its detection by immunohistochemistry has not been successful in the species tested thus far. Citations of studies involving pharmacological interventions are restricted to those that employed site-directed delivery of the cognate peptides or antagonists selective for $\mathrm{CRF}_{1}$ or $\mathrm{CRF}_{2}$.

In discussing anatomical associations between peptide-containing processes and the receptors in question, we recognize the extensive evidence indicating that peptide receptor ligands, including CRF and oxytocin, have physiological actions within the central nervous system that involve their diffusion over considerable distances (Bittencourt and Sawchenko, 2000; Fuxe et al., 2012). It now seems reasonable to hypothesize that there is receptor functionality wherever receptor binding is demonstrated, whether or not the site offers a proximate source for endogenous ligands; nevertheless, cases in which there is a close match between receptor binding and immunohistochemically identified ligandcontaining neuronal processes merit particular attention. The strongest binding signals found in both species in the present study are due to $\mathrm{CRF}_{2}$ in the choroid plexus; the function is unknown. Intense binding or mRNA expression has been found at that site in all rodent and primate species examined thus far (Chalmers et al.,
1995; Rominger et al., 1998; Sanchez et al., 1999; van Pett et al., 2000; Lim et al., 2005).

\section{Nucleus accumbens Distribution of $\mathrm{CRF}_{1}$}

The discovery that the level of $\mathrm{CRF}_{1}$ binding in the shell of the nucleus accumbens is significantly greater in solitary Cape mole-rats than in eusocial naked mole-rats is noteworthy. Previous research (Lim et al., 2005) has shown that $\mathrm{CRF}_{1}$ binding at this site is at a greater level in meadow and montane voles, which are promiscuous and socially independent and show minimal paternal care for offspring (Shapiro and Dewsbury, 1990; Salo et al., 1993), than in prairie and pine voles, which are monogamous and exhibit pair-bonding and biparental care (Getz et al., 1981; Gruder-Adams and Getz, 1985). In rats, this nucleus displays only a moderate level of $\mathrm{CRF}_{1}$ binding and mRNA expression (De Souza et al., 1985; Aguilera et al., 1987; Rominger et al., 1998; van Pett et al., 2000); in mice, the level of expression at this site is low (van Pett et al., 2000).

\section{Distribution of CRF}

In naked mole-rats, the rostral shell of the nucleus accumbens contains CRF-ir processes at an extremely low density; they are not found at this site in Cape mole-rats. However, caudal to the $\mathrm{CRF}_{1}$ binding sites in this nucleus in naked mole-rats, there is a cluster of CRF-ir processes. A similar dissociation is found in prairie and meadow voles, in which CRF-ir processes and CRF mRNA expression are limited to the caudal part of the nucleus (Lim et al., 2006, 2007). This restricted distribution is also found in rats for CRF-ir processes and for CRF-ir cell bodies following intracerebroventricular colchicine treatment (Swanson et al., 1983).

\section{Relations between the distributions of $C R F_{1}$ and $C R F$}

For each of the rodent species discussed here, it seems that activation of $\mathrm{CRF}_{1}$ by $\mathrm{CRF}$ in the rostral shell of the nucleus accumbens would depend on diffusion of the ligand from elsewhere; for naked mole-rats, prairie voles, and meadow voles, the cluster of CRF-ir processes in the caudal part of this nucleus is a possible source. The reported species differences in the density of the binding suggest that local $\mathrm{CRF}_{1}$-mediated functions may be particularly significant in solitary Cape mole-rats and socially independent voles.

\section{Distribution of $\mathrm{CRF}_{2}$}

$\mathrm{CRF}_{2}$ binding is not detected in the nucleus accumbens in naked or Cape mole-rats. In contrast, it is present in the shell of the nucleus in voles (Lim et al., 2005); the 
high or intense levels of $\mathrm{CRF}_{2}$ binding in the caudal (septal) pole of this nucleus in the two pair-bonding species are significantly greater than the weak to moderate levels in the two socially independent species (Lim et al., 2005, 2006). $\mathrm{CRF}_{2}$ binding has been found at a low level in this nucleus in rats (Rominger et al., 1998), but expression of its mRNA has not been detected at this site in either rats or mice (van Pett et al., 2000).

\section{Distribution of urocortins}

In keeping with its lack of $\mathrm{CRF}_{2}$ binding, the nucleus accumbens in naked and Cape mole-rats lacks processes immunoreactive for its ligand, Ucn 3. In voles, Ucn 1-ir processes are absent from this site; mapping immunoreactivity for Ucn 2 or Ucn 3 has not been possible (Lim et al., 2006, 2007). In rats, Ucn 2 mRNA is not expressed in the nucleus accumbens (Reyes et al., 2001), but Ucn 3-ir processes are found at a minimal density at that site (Li et al., 2002; Wittmann et al., 2009), as is the case for Ucn 1-ir processes (Bittencourt et al., 1999).

\section{Relations between the distributions of $\mathrm{CRF}_{2}$ and urocortins}

The evidence for no more than a minimal presence of endogenous ligands for $\mathrm{CRF}_{2}$ (urocortins or $\mathrm{CRF}$ ) in the nucleus accumbens in voles and rats indicates that activation of local $\mathrm{CRF}_{2}$ in those species would depend on ligand diffusion. In contrast, the two mole-rat species studied here appear to lack all prerequisites for $\mathrm{CRF}_{2}$-mediated functions at this site.

\section{Species-related functions of $C R F_{1}$ and $C R F_{2}$}

The level of $\mathrm{CRF}_{1}$ binding in the shell of the nucleus accumbens is greater in solitary Cape mole-rats than in eusocial naked mole-rats. A previous study found a greater level of binding in socially independent vole species than in pair-bonding vole species (Lim et al., 2005). The level of $\mathrm{CRF}_{1}$ binding at this site is positively correlated with the degree of isolation-potentiated startle displayed by rats (Nair et al., 2005). Furthermore, CRF administered to this site potentiates startle in isolated rats but not in group-housed rats (Nair et al., 2005). We speculate that the relatively high level of $\mathrm{CRF}_{1}$ binding in the shell of the nucleus accumbens in solitary Cape mole-rats contributes to their generally high level of intolerance of conspecifics (Bennett and Jarvis, 1988; Jarvis and Bennett, 1991; Ganem and Bennett, 2004). In contrast, we have previously argued that the abundance of oxytocin receptor binding and oxytocinneurophysin-immunoreactive processes in the nucleus accumbens of naked mole-rats may reflect their eusociality, alloparenting behavior, and potential for reproductive attachments; in Cape mole-rats, oxytocin and its receptors are well-nigh absent from this site (Kalamatianos et al., 2010).

$\mathrm{CRF}_{2}$ binding is not present in the nucleus accumbens in naked or Cape mole-rats; this differentiates these animals from voles and rats (Rominger et al., 1998; Lim et al., 2005). Activation of this receptor in the septal pole of the shell of the nucleus accumbens, possibly in concert with activation of $\mathrm{CRF}_{1}$, contributes to partner preference and pair-bonding in monogamous voles (Lim et al., 2005, 2007). In contrast, CRF administered to this site has no effect on partner preference in polygamous meadow voles, which display a lower level of local $\mathrm{CRF}_{2}$ binding (Lim et al., 2007). Rats, which are also non-pair-bonding animals, display a low level of $\mathrm{CRF}_{2}$ binding in this nucleus (Rominger et al., 1998). Given that the mole-rats studied here were either subordinate members of a colony or solitary animals captured outside the breeding season, the absence of a neural mechanism believed to promote partner preference is not surprising. Nevertheless, it will be important to establish whether this feature applies to the reproductive members of a naked mole-rat colony.

\section{Cerebral cortex \\ Distribution of $\mathrm{CRF}_{1}$}

Within the cerebral cortex, naked and Cape mole-rats exhibit an intense level of $\mathrm{CRF}_{1}$ binding in the cingulate cortex; the levels in the piriform cortex and somatosensory cortex in naked mole-rats (intense and high, respectively) are significantly greater than those in Cape molerats. The research on voles shows that the levels of $\mathrm{CRF}_{1}$ binding in the cingulate cortex and other neocortical fields are equivalent (moderate or high) in monogamous prairie and promiscuous meadow species but significantly greater in the promiscuous montane species (low or moderate) than in the monogamous pine species (weak; Lim et al., 2005). Moderate levels of $\mathrm{CRF}_{1}$ binding are found in the cerebral cortex in rats (De Souza et al., 1985; Aguilera et al., 1987) and rhesus monkeys (Sanchez et al., 1999). The levels of $\mathrm{CRF}_{1}$ mRNA expression in the neocortex and piriform cortex in rats and mice are moderate or high (van Pett et al., 2000).

\section{Distribution of CRF}

CRF-ir processes and cell bodies are detected sporadically across all neocortical fields in both mole-rat species; a similar distribution is seen in rats (Merchenthaler, 1984). Weak neocortical CRF immunoreactivity is also found in voles (Lim et al., 2006).

\section{Relations between the distributions of $\mathrm{CRF}_{1}$ and $C R F$}

Given the correspondence between the distributions of $\mathrm{CRF}_{1}$ binding and CRF-ir processes across the cerebral 
cortex, it seems that this receptor can be activated by locally released CRF in all the rodent species discussed here.

\section{Distribution of $\mathrm{CRF}_{2}$}

$\mathrm{CRF}_{2}$ binding is found at low or moderate levels in the cerebral cortex in naked and Cape mole-rats; in these species, levels are equivalent in the cingulate cortex and piriform cortex but are greater in Cape mole-rats in the somatosensory cortex. Previous research has identified no significant differences between monogamous and promiscuous vole species in the low or moderate levels of $\mathrm{CRF}_{2}$ binding detected in their neocortical fields (Lim et al., 2005). In rats and rhesus monkeys, the level of neocortical $\mathrm{CRF}_{2}$ binding is low (Rominger et al., 1998; Sanchez et al., 1999). Expression of $\mathrm{CRF}_{2}$ mRNA in the cingulate cortex and other neocortical fields has been reported to be undetectable in rats (Chalmers et al., 1995), but weak levels were subsequently observed in the piriform cortex and in layer $\mathrm{VI}$ of the isocortex in rats and mice (van Pett et al., 2000) and in layers I-VI of the prefrontal cortex, cingulate cortex, and entorhinal cortex in rhesus monkeys (Sanchez et al., 1999). It is important to note that the present findings concerning the specific location and intensity of $\mathrm{CRF}_{2}$ binding in the cerebral cortex differ from those reported for other species. In naked mole-rats, the $\mathrm{CRF}_{2}$ binding is concentrated in the superficial and deep layers, somewhat similar to the distribution of $\mathrm{CRF}_{1}$ binding in this species. In contrast, in Cape molerats, the binding for these two receptors seems regionally differentiated and in some respects complementary, the $\mathrm{CRF}_{2}$ binding being most prominent in superficial to intermediate layers in the lateral fields. These unusual findings merit further attention.

\section{Distribution of urocortins}

Ucn 3-ir processes are not seen in the neocortex or piriform cortex in either naked or Cape mole-rats; in rats, they are found only in the medial entorhinal region (Li et al., 2002; Wittmann et al., 2009). Ucn 1-ir processes have not been detected in the cerebral cortex in voles (Lim et al., 2006); in rats they are sparse and mostly restricted to the temporal cortex (Bittencourt et al., 1999). The cerebral cortex lacks Ucn 2 mRNA expression in rats (Reyes et al., 2001).

\section{Relations between the distributions of $\mathrm{CRF}_{2}$ and urocortins}

The general dearth of immunoreactivity for Ucn 1 or 3 in the cerebral cortex of the rodents discussed here suggests that activation of $\mathrm{CRF}_{2}$ in the various cortical fields would depend on diffusion of urocortins or locally released CRF.

\section{Species-related functions of $C R F_{1}$ and $C R F_{2}$}

The functional significance of $\mathrm{CRF}_{1}$ and $\mathrm{CRF}_{2}$ in the cerebral cortex remains largely obscure. An unexpected $\mathrm{CRF}_{1}$-dependent anxiolytic effect has been reported following bilateral injection of CRF into the frontal cortex in rats (Zieba et al., 2008). In vitro, this peptide depresses field potentials in cortical slices that are partially disinhibited by antagonists for $\mathrm{GABA}_{A}$ and $G A B A_{B}$ (Zieba et al., 2008); when infused into the rat sensorimotor cortex in vivo, it depresses excitatory monosynaptic field potentials evoked in layers $\mathrm{II} / \mathrm{II}$ and $\mathrm{V}$ (Froc and Christie, 2005).

Chronic isolation has been found to increase $\mathrm{CRF}_{1}$ binding in the rat cingulate cortex, with a rising trend in the piriform cortex and a falling trend in the frontal cortex (Ehlers et al., 1993). In the latter region, the expression of $\mathrm{CRF}_{1}$ mRNA is reduced by 10 days of unpredictable stress (Iredale et al., 1996); 3 hours of restraint stress has the opposite effect (Meng et al., 2011). In the absence of experimental interventions, the present findings and previous studies of other species reveal weak to moderate levels of $\mathrm{CRF}_{1}$ binding at most cortical sites; but relatively high levels are apparent in the cingulate cortex in naked and Cape molerats and in the piriform cortex in naked mole-rats. For $\mathrm{CRF}_{2}$ binding, the levels are generally weak to moderate.

\section{Septal nuclei \\ Distribution of $\mathrm{CRF}_{1}$}

$\mathrm{CRF}_{1}$ binding is not detected in the septal nuclei in naked or Cape mole-rats. The levels of binding and mRNA expression for $\mathrm{CRF}_{1}$ in the lateral septal nuclei are low in rats and mice (De Souza et al., 1985; Aguilera et al., 1987; Chalmers et al., 1995; van Pett et al., 2000) and undetectable in rhesus monkeys (Sanchez et al., 1999). In contrast, moderate or high levels of $\mathrm{CRF}_{1}$ binding are found in the lateral septal nuclei in one of the monogamous vole species (pine) and in one of the polygamous vole species (montane); the other monogamous and polygamous vole species (prairie and meadow) exhibit low levels of $\mathrm{CRF}_{1}$ binding in these nuclei (Lim et al., 2005).

\section{Distribution of CRF}

CRF-ir processes form a dense plexus within the ventral lateral septal nucleus in naked mole-rats. In Cape molerats, these processes are distributed across the ventral and intermediate lateral septal nuclei; a comparable distribution is seen in rats, which also display a few 
scattered CRF-ir cell bodies in the ventral lateral septal nucleus following colchicine treatment (Swanson et al., 1983). Immunoreactivity for CRF has not been detected in the septal nuclei in prairie or meadow voles (Lim et al., 2006).

\section{Relations between the distributions of $\mathrm{CRF}_{1}$ and $C R F$}

The absence of binding signals for $\mathrm{CRF}_{1}$ in the septal nuclei in naked and Cape mole-rats raises questions about the local role for the dense CRF-ir processes in this region in these species. In contrast, it seems that activation of $\mathrm{CRF}_{1}$ by $\mathrm{CRF}$ in the lateral septal nuclei in voles would depend on diffusion of the ligand to these sites.

\section{Distribution of $\mathrm{CRF}_{2}$}

$\mathrm{CRF}_{2}$ binding is found throughout the lateral septal nuclei in Cape mole-rats and predominantly in the ventral and intermediate lateral septal nuclei in naked mole-rats; the intense level in Cape mole-rats is significantly greater than the moderate level in naked molerats. The levels of $\mathrm{CRF}_{2}$ binding and mRNA expression in the lateral septal nuclei have been reported to be high in rats and mice (Chalmers et al., 1995; Rominger et al., 1998; van Pett et al., 2000) and moderate in rhesus monkeys (Sanchez et al., 1999). Moderate or high levels of $\mathrm{CRF}_{2}$ binding are found in the lateral septal nuclei in one of the monogamous vole species (prairie) and in both polygamous vole species (meadow and montane); significantly greater levels are present at these sites in the other monogamous species (pine; Lim et al., 2005).

\section{Distribution of urocortins}

In naked mole-rats, the ventral lateral septal nucleus contains Ucn 3-ir processes in an intense plexus comparable to that found at this site for CRF-ir processes. A similarly restricted distribution of Ucn 3-ir processes is present in Cape mole-rats. In rats, these processes are detected at a high density in the ventral and intermediate lateral septal nuclei (Li et al., 2002; Wittmann et al., 2009), and Ucn 1-ir processes are located predominantly within the intermediate lateral septal nucleus (Bittencourt et al., 1999); Ucn 2 mRNA is not expressed in these nuclei (Reyes et al., 2001). In voles, immunoreactivity for Ucn 1 is not detected in the septal nuclei (Lim et al., 2006).

\section{Relations between the distributions of $\mathrm{CRF}_{2}$ and urocortins}

Although $\mathrm{CRF}_{2}$ binding is present at an intense level throughout the lateral septal nuclei in Cape mole-rats and at a lower level in the ventral and intermediate nuclei in naked mole-rats, Ucn 3-ir processes are restricted to the ventral nucleus in both species. This suggests that activation of $\mathrm{CRF}_{2}$ by Ucn 3 in the intermediate and dorsal nuclei would depend on diffusion of this peptide or on the abundant local CRF. Further research is needed to investigate whether locally released Ucn 1 could act as a ligand for $\mathrm{CRF}_{2}$ in this region in the mole-rats; such a function seems possible for rats but appears to be excluded for the vole species.

\section{Species-related functions of $C R F_{1}$ and $C R F_{2}$}

The lateral septum has been extensively implicated in aggression and social recognition/discrimination in rats, mice, and hamsters (Kollack-Walker et al., 1997; Landgraf et al., 2003; Haller et al., 2006; Beiderbeck et al., 2007). The emotional or social functions that may be mediated by $\mathrm{CRF}_{1}$ in this region remain obscure. The local level of $\mathrm{CRF}_{1}$ binding has been reported to be substantial in only one of the pair-bonding vole species and one of the socially independent vole species; in all the other species discussed here, it is at a low level or absent. Similarly, the septal nuclei lack oxytocin receptor binding sites in naked and Cape mole-rats (Kalamatianos et al., 2010) and in the evolutionarily related New World guinea pigs (Tribollet et al., 1992; Huchon and Douzery, 2001; Kalamatianos et al., 2005). However, oxytocin receptor binding is present in the lateral septum in voles, and its density shows a negative correlation with the degree of alloparental behavior both within and between the species (Olazabal and Young, 2006). In contrast, $\mathrm{CRF}_{2}$ binding is found in the lateral septum at moderate or intense levels in all species that have been investigated. Activation of $\mathrm{CRF}_{2}$ in this region promotes anxiety-related behaviors in mice; an effect that is enhanced by stressful conditions (Henry et al., 2006). Furthermore, stress-induced behaviors can be suppressed in mice and rats by preventing local $\mathrm{CRF}_{2}$ activation (Radulovic et al., 1999; Bakshi et al., 2002). The present study shows a significantly lower level of $\mathrm{CRF}_{2}$ binding in the lateral septum in naked mole-rats than in Cape mole-rats. We speculate that this relatively low level contributes to the prosocial, cooperative behaviors displayed by naked mole-rats.

\section{Extended amygdala Distribution of $\mathrm{CRF}_{1}$}

In naked and Cape mole-rats, the highest levels of $\mathrm{CRF}_{1}$ binding within the extended amygdala are found in the basolateral complex; the level of binding is significantly greater in the basolateral nucleus in naked mole-rats than in Cape mole-rats. The two species 
exhibit equivalent low levels in the central nucleus and moderate levels in the medial nucleus and amygdalostriatal transition area; the low levels of binding in the BNST are also equivalent. In rats, $\mathrm{CRF}_{1}$ binding is at a moderately high level in the basolateral nucleus and at lower levels in the medial and central nuclei (De Souza et al., 1985; Aguilera et al., 1987). The basolateral nucleus expresses $\mathrm{CRF}_{1}$ mRNA at a high level in rats and at a low level in mice (Chalmers et al., 1995; van Pett et al., 2000); both of these species show low or moderate expression levels in the medial, basomedial, and cortical nuclei (van Pett et al., 2000). The BNST in rats exhibits a moderate level of $\mathrm{CRF}_{1}$ binding (De Souza et al., 1985; Aguilera et al., 1987); expression of $\mathrm{CRF}_{1}$ mRNA in this region is also at a moderate level in rats but at a lower level in mice (Chalmers et al., 1995; van Pett et al., 2000). In rhesus monkeys, CRF $_{1}$ binding is at a high level in the lateral amygdaloid nucleus and at lower levels in the medial and central nuclei; its mRNA expression is at a moderate level in the lateral and central nuclei and a low level in the medial nucleus (Sanchez et al., 1999). The BNST in rhesus monkeys exhibits neither $\mathrm{CRF}_{1}$ binding nor $\mathrm{CRF}_{1}$ mRNA expression (Sanchez et al., 1999). The research on voles shows that the binding levels for this receptor in the amygdaloid nuclei are consistently minimal in one of the monogamous species (pine) and low in one of the polygamous species (montane); in the other monogamous and polygamous vole species (prairie and meadow), the levels of $\mathrm{CRF}_{1}$ binding in the various amygdaloid nuclei range from undetectable to moderate, the highest levels within this range being found in the cortical amygdaloid nucleus (Lim et al., 2005). No significant differences have been identified between the monogamous and the polygamous species for $\mathrm{CRF}_{1}$ binding in the various amygdaloid nuclei (Lim et al., 2005). In the BNST, CRF 1 binding is at a minimal level in the four vole species that have been studied (Lim et al., 2005).

\section{Distribution of CRF}

Among the amygdaloid nuclei, CRF-ir processes are found in the central nucleus at a low density in naked mole-rats and at a high density in Cape mole-rats. In the BNST, their density is low immediately ventrolateral to the base of the lateral ventricle in the dorsal part of the lateral division in naked mole-rats. In contrast, Cape mole-rats exhibit a high density of these processes throughout the BNST, ventral, dorsal, and lateral to the anterior commissure. In rats, CRF-ir processes are seen at a high density in the central amygdaloid nucleus and more diffusely in the medial, lateral, basolateral, basomedial, and cortical nuclei; most of the amygdaloid CRF-ir cell bodies detected following colchicine treatment are in the central nucleus (Swanson et al., 1983; Merchenthaler, 1984). In mice and in the biparental caviomorph rodent Octodon degus, there is a particularly dense plexus of CRF-ir processes in the central nucleus (Asan et al., 2005; Seidel et al., 2011). In comparison with rats, mice display a lower level of CRF mRNA expression in the central nucleus and, in the absence of colchicine, fewer CRF-ir cell bodies at this site (Asan et al., 2005). CRF-ir processes and mRNA are also found in the amygdalostriatal area in rats and mice; the density of these processes shows considerable variation between strains of mice (Asan et al., 2005). In rats, CRF-ir processes and cell bodies are abundant throughout the BNST (Swanson et al., 1983). In prairie and meadow voles, these processes are found at a high density in the central amygdaloid nucleus and BNST, with no apparent species or sex differences (Lim et al., 2006).

\section{Relations between the distributions of $\mathrm{CRF}_{1}$ and $C R F$}

For each of the rodent species in which the amygdaloid distribution of $\mathrm{CRF}_{1}$ binding has been investigated, the principal location of CRF-ir processes, the central nucleus, does not correspond to the principal speciesspecific site for $\mathrm{CRF}_{1}$ binding. In the case of naked mole-rats, the central nucleus has a density of CRF-ir processes that is uniquely low among the species discussed here. It seems that activation of $\mathrm{CRF}_{1}$ at most of the amygdaloid sites would depend on diffusion of CRF. In the BNST, $\mathrm{CRF}_{1}$ binding is detected in all the rodent species studied, the level being moderate in mole-rats and rats but minimal in voles. Abundant CRFir processes are found throughout the BNST in all these species apart from naked mole-rats, in which the low density restricted to the dorsal part of the lateral division is noteworthy as an exception.

\section{Distribution of $\mathrm{CRF}_{2}$}

In naked and Cape mole-rats, $\mathrm{CRF}_{2}$ binding levels within the amygdaloid nuclei are low or moderate, the highest levels within this range being found in the lateral nucleus; the level of binding is significantly greater in the basolateral nucleus in naked mole-rats than in Cape mole-rats. The two species exhibit equivalent low levels in the central and medial nucleus. The intense level of $\mathrm{CRF}_{2}$ binding in the amygdalostriatal transition area in Cape mole-rats greatly exceeds the low level at this site in naked mole-rats. Similarly, the level of $\mathrm{CRF}_{2}$ binding in the lateral division of the BNST, although relatively low, is greater in Cape mole-rats than in naked mole-rats. In rats, there is a moderate level of $\mathrm{CRF}_{2}$ 
binding throughout the amygdaloid nuclei and BNST (Rominger et al., 1998). mRNA expression for this receptor in rats and mice is at a moderate level in the medial, basomedial, and cortical amygdaloid nuclei and BNST, at a low level in the basolateral amygdaloid nucleus, and undetectable in the central amygdaloid nucleus (Chalmers et al., 1995; van Pett et al., 2000). Within the amygdala in voles, moderate levels of $\mathrm{CRF}_{2}$ binding are found in one of the monogamous species (prairie) and in one of the polygamous species (meadow); the other monogamous and polygamous vole species (pine and montane) exhibit low levels of $\mathrm{CRF}_{2}$ binding across this region (Lim et al., 2005). No significant differences have been identified between the monogamous and polygamous vole species for this parameter in the various amygdaloid nuclei (Lim et al., 2005). The four vole species display low or moderate levels of $\mathrm{CRF}_{2}$ binding in the BNST apart from its caudal region, where high levels are found (Lim et al., 2005). In rhesus monkeys, the level of $\mathrm{CRF}_{2}$ binding is minimal or low within the amygdaloid nuclei and the BNST; mRNA expression for this receptor is detected at only minimal levels in the medial and central amygdaloid nuclei but at a moderate level in the BNST (Sanchez et al., 1999).

\section{Distribution of urocortins}

Among the amygdaloid nuclei, Ucn 3-ir processes are found at a low density in the medial nucleus in naked and Cape mole-rats. In the BNST, they are present dorsal to the anterior commissure at a moderate density in naked mole-rats and at a lower density in Cape molerats. In rats, Ucn 3-ir processes are detected at a high density in the medial amygdaloid nucleus, where Ucn 3 mRNA is expressed; scattered Ucn 3-ir processes are also seen in the basomedial, cortical and central nuclei (Lewis et al., 2001; Li et al., 2002; Wittmann et al., 2009). The amygdalostriatal transition area lacks immunoreactivity for Ucn 3 or CRF in naked or Cape molerats; however, a plexus of CRF-ir processes is present at this site in rats and in various strains of mice (Asan et al., 2005). The BNST in rats contains Ucn 3-ir processes at a moderate or high density, along with Ucn 3 mRNA expression (Lewis et al., 2001; Li et al., 2002; Wittmann et al., 2009). Ucn 1-ir processes in rats are sparse within the extended amygdala, apart from their moderately dense presence in the central nucleus and BNST (Bittencourt et al., 1999). In the four vole species that have been studied, immunoreactivity for Ucn 1 is not seen within the amygdaloid nuclei or BNST (Lim et al., 2006). The mRNA for Ucn 2 is not expressed in the amygdaloid nuclei or BNST in rats (Reyes et al., 2001).

\section{Relations between the distributions of $\mathrm{CRF}_{2}$ and urocortins}

$\mathrm{CRF}_{2}$ binding is detected across the amygdaloid nuclei at low or moderate levels in naked mole-rats and Cape mole-rats, rats, and voles. Among the candidates for endogenous local ligands, Ucn 1 is absent from these nuclei in voles, but there is a moderate density of Ucn 1-ir processes in the central nucleus in rats. Ucn 3-ir processes are detected at a low density in the central nucleus in Cape mole-rats and at a low density in the medial nucleus in naked mole-rats, a site that displays a high density of these processes in rats. It seems that activation of $\mathrm{CRF}_{2}$ by Ucn 3 or by CRF outside the medial or central nucleus in naked mole-rats and outside the central nucleus in Cape mole-rats would depend on diffusion of these ligands. The intense level of $\mathrm{CRF}_{2}$ binding found in the amygdalostriatal transition area in Cape mole-rats with no associated Ucn 3 or CRF is particularly intriguing. The BNST exhibits some overlap between $\mathrm{CRF}_{2}$ binding and Ucn 3-ir processes in the two mole-rat species and in rats; moderately dense Ucn 1-ir processes are also found in this region in rats. Local activation of $\mathrm{CRF}_{2}$ by those peptides seems likely.

\section{Species-related functions of $\mathrm{CRF}_{1}$ and $\mathrm{CRF}_{2}$ Basolateral nucleus}

In monogamous and polygamous voles, $\mathrm{CRF}_{1}$ binding levels are weak or low throughout the amygdala; but in naked mole-rats, Cape mole-rats, rats, and rhesus monkeys, a relatively high level is present in the basolateral nucleus. This disparity raises questions about speciesspecific functions of $\mathrm{CRF}_{1}$ in this nucleus, a nodal site involved in multimodal sensory processing and consolidating memories of threatening circumstances (Shekhar et al., 2005; Mclntyre et al., 2012). Acute stress elicits CRF release in this region (Merlo Pich et al., 1995). Acting via $\mathrm{CRF}_{1}, \mathrm{CRF}$ increases the amplitude of field potentials recorded in the rat basolateral nucleus after excitatory afferent stimulation; such actions may raise the salience of aversive stimuli and enhance the consolidation of associated memories (Ugolini et al., 2008). Social interactions in rats are inhibited by activation of $\mathrm{CRF}_{1}$ in the basolateral nucleus (Gehlert et al., 2005). Brief exposure to a ferret leads to decreased feeding and increased grooming in rats; these responses are suppressed by pretreatment with a $\mathrm{CRF}_{1}$ antagonist, but not a $\mathrm{CRF}_{2}$ antagonist, in the basolateral nucleus (Jochman et al., 2005). There is evidence that local activation of $\mathrm{CRF}_{1}$ has enduring effects; thus, if social defeat in a mouse is immediately followed by infusion of a $\mathrm{CRF}_{1}$ antagonist into the basolateral nucleus, the 
fear response elicited by exposure to a nonaggressive intruder 24 hours later is inhibited (Robison et al., 2004). Our comparisons between the two mole-rat species showed $\mathrm{CRF}_{1}$ binding to be at a significantly greater level in the basolateral nucleus in naked molerats. We speculate that this may contribute to the systems that protect colony autonomy by maintaining a high level of xenophobia, even against genetically closely related foreign conspecifics, to maintain colony autonomy (O'Riain and Jarvis, 1997).

$\mathrm{CRF}_{2}$ binding in the basolateral nucleus is at a higher level in naked mole-rats than in Cape mole-rats; no significant differences between vole species have been found for this parameter. The physiological and behavioral roles of $\mathrm{CRF}_{2}$ at this site are unknown.

\section{Central nucleus}

The central nucleus regulates autonomic and behavioral reactions to adverse conditions (Kovacs, 2013). Various studies on rats implicate $\mathrm{CRF}_{1}$ at this site in these reactions. Chronic local infusion of a $\mathrm{CRF}_{1}$ antisense oligonucleotide reduces anxiety-related behavior following social defeat (Liebsch et al., 1995). Blocking $\mathrm{CRF}_{1}$ activation inhibits synaptic facilitation in this nucleus via a postsynaptic mechanism (Fu and Neugebauer, 2008). Pain-related vocalizations are inhibited by local microdialysis of a $\mathrm{CRF}_{1}$ antagonist, but not a $\mathrm{CRF}_{2}$ antagonist ( $\mathrm{Fu}$ and Neugebauer, 2008). Pretreatment with a $\mathrm{CRF}_{1}$ antagonist at this site reduces shockinduced freezing and anxiety-related behavior following restraint stress (Bakshi et al., 2002; Henry et al., 2006). The present study detected equivalent levels of $\mathrm{CRF}_{1}$ binding in the central amygdaloid nucleus in naked and Cape mole-rats; similarly, there is no significant variation in this parameter between monogamous and polygamous vole species.

Blocking $\mathrm{CRF}_{2}$ activation facilitates synaptic transmission in the rat central nucleus by presynaptic inhibition of GABAergic transmission (Fu and Neugebauer, 2008). Local activation of $\mathrm{CRF}_{2}$ by infusion of a $\mathrm{CRF}_{2}$ agonist decreases self-administration of alcohol in alcoholdependent rats (Funk and Koob, 2007). Equivalent low levels of $\mathrm{CRF}_{2}$ binding are detected at this site in naked and Cape mole-rats; however, the latter species exhibits a vastly greater level in the adjacent amygdalostriatal transition area. The functional significance of these findings is not clear.

\section{BNST}

Research on rats shows that anxiogenic effects induced by CRF delivered to the BNST or by seven daily sessions of psychological stress can be blocked by infusion of a $\mathrm{CRF}_{1}$ antagonist, but not a $\mathrm{CRF}_{2}$ antagonist, into this region (Sahuque et al., 2006; Tran et al., 2014). Species differences for $\mathrm{CRF}_{1}$ binding in the BNST have not been found in the present study or in previous studies on voles.

The $\mathrm{CRF}_{2}$ binding level in the BNST is significantly greater in Cape mole-rats than in naked mole-rats. No such differences are found between the monogamous and the polygamous voles. Antagonizing these receptors in a hamster that had suffered social defeat on the previous day suppresses the submissive and defensive behavior provoked by a nonaggressive intruder (Cooper and Huhman, 2005). There is evidence for the presence of $\mathrm{CRF}_{2}$ in oxytocin-ir processes that surround CRF-ir cell bodies in the rat BNST; this may provide a mechanism for CRF in the BNST to inhibit the local release of oxytocin (Dabrowska et al., 2011). At this site, oxytocin is implicated in parental behavior in rats (Francis et al., 2000; Champagne et al., 2001) and alloparental behavior in prairie voles (Insel and Shapiro, 1992). Alloparenting is practiced by naked mole-rats and prairie voles; these species show a greater level of oxytocin receptor binding in the BNST than, respectively, Cape mole-rats and montane voles, which never exhibit alloparental behavior (Insel and Shapiro, 1992; Kalamatianos et al., 2010). We speculate that the higher level of $\mathrm{CRF}_{2}$ binding in the BNST of Cape mole-rats contributes to suppressed oxytocinergic signaling at this site.

\section{Hippocampus \\ Distribution of CRF}

$\mathrm{CRF}_{1}$ binding is present at a moderate level in the CA1 subfield and at a low level in the CA2 subfield in both naked and Cape mole-rats. In the CA3 subfield, there is a high level of $\mathrm{CRF}_{1}$ binding in naked mole-rats but only a low level in Cape mole-rats. In the dentate gyrus, the moderate level of $\mathrm{CRF}_{1}$ binding in naked mole-rats, predominantly in the molecular layer, exceeds that in Cape mole-rats, where it is restricted to the polymorph layer. In contrast, in the four vole species that have been studied, the binding signals are either minimal or absent in CA1, CA2, and CA3 and the dentate gyrus (Lim et al., 2005). For rats, $\mathrm{CRF}_{1}$ binding in the hippocampus and dentate gyrus has been reported to be low (De Souza et al., 1985; Aguilera et al., 1987); $\mathrm{CRF}_{1}$ mRNA is found at a moderate level in CA 1 and CA3 and in the polymorph layer of the dentate gyrus in rats and mice, with the granular layer exhibiting a minimal level in rats but no signal in mice (van Pett et al., 2000). In rhesus monkeys, neither binding nor mRNA expression for $\mathrm{CRF}_{1}$ is detected in CA1, CA2, or CA3, but the granular layer of the dentate gyrus exhibits a moderate level of binding and a high level of expression (Sanchez et al., 1999). 


\section{Distribution of CRF}

In naked mole-rats, diffuse CRF-ir profiles are found in the CA1, CA2, and CA3 subfields and in the molecular layer of the dentate gyrus; in contrast, in Cape molerats, they are seen only in CA 1 and the polymorph layer of the dentate gyrus. In rats, CRF immunoreactivity has been found in scattered interneurons in CA1 and CA3 and in the dentate gyrus (Merchenthaler et al., 1982; Swanson et al., 1983; Chen et al., 2012). In voles, CRF has not been detected by immunohistochemistry in the hippocampal formation (Lim et al., 2006).

\section{Relations between the distributions of $C R F_{1}$ and $C R F$}

The evidence from this study and from previous research on rats suggests that the distribution of $\mathrm{CRF}_{1}$ binding in the CA1 and CA3 subfields is associated with local sources for CRF. It is the dentate gyrus that provides particularly interesting results here. Diffuse CRF-ir profiles are found in the molecular layer in naked mole-rats and in the polymorph layer in Cape mole-rats; this difference in distribution matches the speciesspecific pattern of $\mathrm{CRF}_{1}$ binding.

\section{Distribution of $\mathrm{CRF}_{2}$}

The dentate gyrus is also highlighted in the findings for hippocampal $\mathrm{CRF}_{2}$ binding. In naked and Cape molerats, $\mathrm{CRF}_{2}$ binding is seen only in the molecular layer, where the level is considerably greater in naked molerats. In contrast, $\mathrm{CRF}_{2}$ binding in pine and montane voles is found at a low level in all hippocampal regions; however, in prairie and meadow voles, the levels are generally moderate except in the CA1 subfield in meadow voles, where the level is intense (Lim et al., 2005). In rats, $\mathrm{CRF}_{2}$ binding is at a low level throughout the hippocampus (Rominger et al., 1998); furthermore, its mRNA expression is low in CA1, CA3, and the granular layer of the dentate gyrus in rats and mice (van Pett et al., 2000). In rhesus monkeys, the level of $\mathrm{CRF}_{2}$ binding is moderate in CA1, low in CA2 and CA3, and undetectable in the dentate gyrus; $\mathrm{CRF}_{2}$ mRNA has not been detected at these sites (Sanchez et al., 1999).

\section{Distribution of urocortins}

Ucn 3-ir profiles are found in CA1-CA3 in naked molerats but only in CA 1 in Cape mole-rats; in rats, they are restricted to the ventral hippocampus (Li et al., 2002; Wittmann et al., 2009). Hippocampal Ucn 1 is seen in sparse processes in rats (Bittencourt et al., 1999) but is not detected in voles (Lim et al., 2006). The mRNA for Ucn 2 is not expressed in the hippocampus in rats (Reyes et al., 2001).

\section{Relations between the distributions of $\mathrm{CRF}_{2}$ and urocortins}

In contrast to voles and rats, in which $\mathrm{CRF}_{2}$ binding is present at low or moderate levels in almost all hippocampal regions, naked and Cape mole-rats exhibit the binding signals only in the molecular layer of the dentate gyrus. In rats, the broad distribution of hippocampal $\mathrm{CRF}_{2}$ binding is not matched by Ucn 3-ir processes but may be complemented by sparse Ucn 1-ir processes. However, in both mole-rat species studied here, there appears to be a complete mismatch between the location of the $\mathrm{CRF}_{2}$ binding, which is exclusively in the molecular layer of the dentate gyrus, and the distribution of Ucn 3-ir processes in the CA subfields. Local activation of $\mathrm{CRF}_{2}$ may involve the diffuse CRF-ir profiles in the molecular layer in naked mole-rats.

\section{Species-related functions of $C R F_{1}$ and $C R F_{2}$}

In response to psychologically adverse conditions, CRF is released from interneurons in the hippocampal pyramidal layer and promotes synaptic efficacy and memory processes in rats; its excitatory effects on pyramidal neurons are mediated by $\mathrm{CRF}_{1}$ (Chen et al., 2012; Maras and Baram, 2012). Activation of those neurons by the modest stress of crowding for 30 minutes can be blocked by a $\mathrm{CRF}_{1}$ antagonist (Chen et al., 2004). Intrahippocampal CRF enhances fear conditioning in mice via $\mathrm{CRF}_{1}$ (Radulovic et al., 1999). In response to the acquisition of learned helplessness, rats suppress $\mathrm{CRF}_{1}$ mRNA expression in the CA3 subfield and dentate gyrus for up to 26 days (Fernandez Macedo et al., 2013). These are the sites at which naked mole-rats display particularly high levels of $\mathrm{CRF}_{1}$ binding; this intensity may favor adaptive processes within their remarkably large hippocampus, but these remain to be elucidated. The relatively high level of $\mathrm{CRF}_{1}$ binding shared by naked and Cape mole-rats in CA1 distinguishes them from the other rodents that have been studied. In contrast, the oxytocin receptor binding in this hippocampal subfield displays a significant difference between naked and Cape mole-rats, the level being higher in the former species; we have argued that this may reflect differences in selective pressure for spatial abilities (Kalamatianos et al., 2010). It is noteworthy that naked mole-rats, in common with other social mole-rat species, occupy more complex burrow systems (with a higher fractal dimension) than solitary Cape mole-rats (Le Comber et al., 2002).

Voltage-sensitive dye imaging in hippocampal slices from mice shows that $\mathrm{CRH}$ increases neuronal activity propagation from the dentate gyrus to CA1 (von Wolff et al., 2011). In Cape mole-rats, $\mathrm{CRF}_{1}$ binding in the 
dentate gyrus is predominantly associated with the polymorph layer; the greater level of binding in the dentate gyrus in naked mole-rats is found in the molecular layer. A study using GFP as a reporter gene for $\mathrm{CRF}_{1}$ expression in mice showed GFP not only in cell bodies in the polymorph layer but also in dense processes in the molecular layer; the latter are believed to correspond to projections from the entorhinal cortex (Justice et al., 2008). It remains to be established whether these particular compartments underlie the different distributions of $\mathrm{CRF}_{1}$ binding in naked and Cape molerats in this region.

The dentate gyrus in naked mole-rats also displays a greater level of $\mathrm{CRF}_{2}$ binding than in Cape mole-rats. The restriction of the binding to the molecular layer in both species is unique among the species that have been studied. $\mathrm{CRF}_{2}$ mRNA in mice shows a transient increase in the dentate gyrus and in CA1 and CA3 3 hours after 1 hour of restraint stress (Sananbenesi et al., 2003). If a selective $\mathrm{CRF}_{2}$ antagonist is administered intrahippocampally shortly before a fearconditioning protocol is commenced 3 hours after restraint, the stress-induced enhancement of the conditioning is prevented (Sananbenesi et al., 2003). Monogamous prairie voles, which normally display a moderate level of $\mathrm{CRF}_{2}$ binding throughout the hippocampus (Lim et al., 2005), respond to chronic isolation with an increase in whole hippocampal $\mathrm{CRF}_{2}$ mRNA (PournajafiNazarloo et al., 2011). It is noteworthy that the naturally solitary Cape mole-rats have an extremely low level of $\mathrm{CRF}_{2}$ binding in comparison with the high level found in the eusocial naked mole-rats. The level is also low in socially noncooperative mice and rats (van Pett et al., 2000).

\section{Medial habenular nucleus Distribution of $\mathrm{CRF}_{1}$}

In the medial habenular nucleus, $\mathrm{CRF}_{1}$ binding is present at a moderate level in Cape mole-rats but is not detected in naked mole-rats. At this site, the level of $\mathrm{CRF}_{1}$ binding is high in prairie voles, low in meadow voles, and minimal in pine and montane voles (Lim et al., 2005). A moderate level of $\mathrm{CRF}_{1}$ binding is found in rats (De Souza et al., 1985), but local expression of $\mathrm{CRF}_{1}$ mRNA is not detected in that species or in mice (van Pett et al., 2000).

\section{Distribution of CRF}

Although the medial habenular nucleus lacks CRF-ir processes in naked and Cape mole-rats, such processes are present at a moderate density in the adjacent paraventricular nucleus of the thalamus; this corresponds to their distribution in rats (Merchenthaler et al., 1982; Swanson et al., 1983). CRF immunoreactivity has not been identified at these sites in voles (Lim et al., 2006).

\section{Relations between the distributions of $C R F_{1}$ and $C R F$}

For all the rodent species mentioned here, it seems that local activation of $\mathrm{CRF}_{1}$ by CRF would depend on diffusion of the ligand from outside the medial habenular nucleus.

\section{Distribution of $\mathrm{CRF}_{2}$}

The level of $\mathrm{CRF}_{2}$ binding in the medial habenular nucleus is intense in Cape mole-rats, significantly greater than the moderate level found in naked molerats. In prairie and meadow voles, the level of binding to this receptor is moderate; in pine and montane voles, it is minimal (Lim et al., 2005). For rats, there is no report of $\mathrm{CRF}_{2}$ binding at this site (Rominger et al., 1998); neither rats nor mice express its mRNA there (van Pett et al., 2000).

\section{Distribution of urocortins}

In naked and Cape mole-rats, Ucn 3-ir processes are absent from the medial habenular nucleus but are present at an extremely low density in the paraventricular nucleus of the thalamus. There is an equivalent distribution of Ucn 3-ir and Ucn 1-ir processes in rats (Bittencourt et al., 1999; Li et al., 2002). The presence of Ucn 1-ir processes was not reported for the medial habenular nucleus in voles (Lim et al., 2006). Ucn 2 mRNA is not expressed at this site in rats (Reyes et al., 2001).

\section{Relations between the distributions of $\mathrm{CRF}_{2}$ and urocortins}

The evidence from mole-rats and rats suggests that activation of $\mathrm{CRF}_{2}$ in the medial habenular nucleus would depend on diffusion of Ucn 1, Ucn 3 or CRF to this site.

\section{Species-related functions of $C R F_{1}$ and $C R F_{2}$}

The habenula is an evolutionarily conserved structure, present in virtually all vertebrate species (Hikosaka, 2010; Viswanath et al., 2013). The medial habenular nucleus is implicated in the regulation of reward and in motivation for voluntary exercise (Hsu and Wang, 2014). Studies on rodents and zebrafish indicate that this nucleus plays a role in behavioral responses to fear-inducing stimuli (Viswanath et al., 2013), including the freezing response to adverse conditions (Hikosaka, 2010). The functions of $\mathrm{CRF}_{1}$ and/or $\mathrm{CRF}_{2}$ at this site are unknown; their levels of binding show a remarkable range across the species discussed here: $\mathrm{CRF}_{1}$ is 
undetected in naked mole-rats but is found at a moderate level in Cape mole-rats and at a high level in prairie voles; $\mathrm{CRF}_{2}$ is present at a remarkably intense level in Cape mole-rats and at a high level in naked mole-rats, but it is absent in rats. We speculate that these receptors modulate local responses to adverse conditions in species-specific ways.

\section{CONCLUSIONS}

There are substantial differences in telencephalic $\mathrm{CRF}_{1}$ and $\mathrm{CRF}_{2}$ binding levels between eusocial naked mole-rats and solitary Cape mole-rats. The sites at which the level of $\mathrm{CRF}_{1}$ binding in naked mole-rats exceeds that in Cape mole-rats include the basolateral amygdaloid nucleus, hippocampal CA3 subfield, and dentate gyrus; in contrast, the level is greater in Cape mole-rats in the shell of the nucleus accumbens and medial habenular nucleus. For $\mathrm{CRF}_{2}$ binding, the sites with a greater level in naked mole-rats include the basolateral amygdaloid nucleus and dentate gyrus, but the septohippocampal nucleus, lateral septal nuclei, amygdalostriatal transition area, BNST, and medial habenular nucleus display a greater level in Cape mole-rats.

Among these sites, the nucleus accumbens is implicated in species-typical aspects of social behavior in voles. This is the only telencephalic nucleus in which the binding level for either $\mathrm{CRF}_{1}$ or $\mathrm{CRF}_{2}$ differs between the monogamous and polygamous voles; furthermore, it differs for both receptor types, the local level being greater for $\mathrm{CRF}_{1}$ binding in the promiscuous species and for $\mathrm{CRF}_{2}$ binding in the monogamous species (Lim et al., $2005,2007)$. The present study identifies a comparable difference between naked and Cape mole-rats in the nucleus accumbens: the solitary species displays a greater level of $\mathrm{CRF}_{1}$ binding. $\mathrm{CRF}_{2}$ binding is not detected at this site in either species of mole-rat.

We have previously reported an abundance of oxytocin receptor binding and oxytocin-neurophysin-ir processes in the nucleus accumbens in eusocial naked mole-rats; this may reflect the eusociality, alloparenting behavior, and potential for reproductive attachments that characterize this species (Kalamatianos et al., 2010). In contrast, there is a dearth of both of those factors at this site in solitary Cape mole-rats, possibly reflecting their asocial life (Kalamatianos et al., 2010). Monogamous voles are the only other rodents in which a substantial level of oxytocin receptor binding has been observed in this nucleus (Insel and Shapiro, 1992; Lim et al., 2005; Beery et al., 2008); the binding is accompanied by oxytocin-immunoreactive processes (Lim et al., 2004). Meadow voles, mice, rats, and guinea pigs also possess oxytocin-containing processes at this site (Castel and Morris, 1988; Dubois-Dauphin et al., 1989; Ross et al., 2009), but these nonmonogamous species display little or no associated oxytocin receptor binding (Insel and Shapiro, 1992; Tribollet et al., 1992; Olazabal and Young, 2006; Beery et al., 2008). Thus, the local level of oxytocin receptor binding rather than the prevalence of oxytocin-containing processes appears to be a significant factor for monogamous voles. In contrast, none of the rodent species that have been studied (Swanson et al., 1983; Lim et al., 2006, 2007; present study) displays more than a minimal density of CRF-ir processes at the site of $\mathrm{CRF}_{1}$ binding in the nucleus accumbens. The available evidence therefore suggests that oxytocin receptor activation in this nucleus involves locally released oxytocin, but local activation of $\mathrm{CRF}_{1}$ requires the diffusion of $\mathrm{CRF}$ to this site. Collectively, these radioligand binding studies (Insel and Shapiro, 1992; Lim et al., 2005; Kalamatianos et al., 2010; present study) indicate that the nucleus accumbens contains levels of oxytocin receptor binding and $\mathrm{CRF}_{1}$ binding that are inversely related; solitary Cape mole-rats and polygamous voles have the greater level of $\mathrm{CRF}_{1}$ binding, but eusocial naked mole-rats and monogamous voles have the greater level of oxytocin receptor binding. The possibility of opposing actions between these systems at this site merits attention.

The animals investigated in this study were male and either nonreproductive, subordinate naked mole-rats or Cape mole-rats captured outside their breeding season. Thus, by restricting the study to animals with low levels of testosterone (Bennett and Jarvis, 1988; Faulkes and Abbott, 1991; Zhou et al., 2013), we sought to exclude activational effects of that steroid and focus on species-specific differences. Unlike prairie voles, most naked mole-rats fail to enter puberty and to establish any form of reproductive attachment during their life; nevertheless, they have the potential to succeed the queen or her consorts. It will be important to determine whether the transition from the nonreproductive state in naked mole-rats is accompanied by regional changes in the expression of $\mathrm{CRF}_{1}$ and/or $\mathrm{CRF}_{2}$ and in the availability of their endogenous ligands. Similarly, whether such changes occur in female Cape mole-rats in association with the brief period in which they display maternal behavior warrants investigation.

The research presented here was not designed to elucidate causal connections between species differences in telencephalic CRF-related networks and species differences in social behavior; the functional significance of the reported differences remains to be determined. By analogy with findings in monogamous voles (Insel and Shapiro, 1992; Olazabal and Young, 2006), we have previously hypothesized that the abundance of 
oxytocin receptor binding in the nucleus accumbens in eusocial naked mole-rats reflects their prosocial behaviors (Kalamatianos et al., 2010). The results of the present study prompt the complementary hypothesis that the abundance of $\mathrm{CRF}_{1}$ binding at this site in Old World solitary Cape mole-rats, as in New World polygamous voles (Lim et al., 2005), reflects the lack of affiliative behavior in those species.

\section{ACKNOWLEDGMENTS}

We gratefully acknowledge Dr Larry Young and the late Dr Wylie Vale for the kind gifts of, respectively, CP154,526 and the urocortin 3 antiserum.

\section{CONFLICT OF INTEREST STATEMENT}

The authors declare no actual or potential conflicts of interest.

\section{ROLE OF AUTHORS}

All authors had full access to all the data in the study and take responsibility for the integrity of the data and the accuracy of the data analysis. Study concept and design: CWC, TK, CGF, NCB. Acquisition of data: CWC, TK, MKO, RP. Analysis and interpretation of data: CWC, TK, RP. Drafting of the manuscript: CWC, RP, TK. Comments on the manuscript: CGF, NCB. Acquisition of funding: CWC, CGF, NGF.

\section{LITERATURE CITED}

Aguilera G, Millan MA, Hauger RL, Catt KJ. 1987. Corticotropin-releasing factor receptors: distribution and regulation in brain, pituitary, and peripheral tissues. Ann $N$ Y Acad Sci 512:48-66.

Asan E, Yilmazer-Hanke DM, Eliava M, Hantsch M, Lesch KP, Schmitt A. 2005. The corticotropin-releasing factor (CRF)-system and monoaminergic afferents in the central amygdala: investigations in different mouse strains and comparison with the rat. Neuroscience 131:953-967.

Bakshi VP, Smith-Roe S, Newman SM, Grigoriadis DE, Kalin $\mathrm{NH}$. 2002. Reduction of stress-induced behavior by antagonism of corticotropin-releasing hormone $2(\mathrm{CRH} 2)$ receptors in lateral septum or $\mathrm{CRH} 1$ receptors in amygdala. J Neurosci 22:2926-2935.

Bale TL, Vale WW. 2004. CRF and CRF receptors: role in stress responsivity and other behaviors. Annu Rev Pharmacol Toxicol 44:525-557.

Bangasser DA. 2013. Sex differences in stress-related receptors: "micro" differences with "macro" implications for mood and anxiety disorders. Biol Sex Differ 4:2.

Beery AK, Lacey EA, Francis DD. 2008. Oxytocin and vasopressin receptor distributions in a solitary and a social species of tuco-tuco (Ctenomys haigi and Ctenomys sociabilis). J Comp Neurol 507:1847-1859.

Beiderbeck DI, Neumann ID, Veenema AH. 2007. Differences in intermale aggression are accompanied by opposite vasopressin release patterns within the septum in rats bred for low and high anxiety. Eur J Neurosci 26:35973605.
Bennett NC, Jarvis JUM. 1988. The reproductive biology of the Cape mole-rat, Georychus capensis (Rodentia, Bathyergidae). J Zool 214:95-106.

Bennett NC, Faulkes CG, Jarvis JUM. 1999. Socially-induced infertility incest avoidance and the monopoly of reproduction in cooperatively breeding African mole-rats. Adv Stud Behav 28:75-113.

Biag J, Huang Y, Gou L, Hintiryan H, Askarinam A, Hahn JD, Toga AW, Dong HW. 2012. Cyto- and chemoarchitecture of the hypothalamic paraventricular nucleus in the C57BL/6J male mouse: a study of immunostaining and multiple fluorescent tract tracing. J Comp Neurol 520:633.

Bittencourt JC, Sawchenko PE. 2000. Do centrally administered neuropeptides access cognate receptors?: an analysis in the central corticotropin-releasing factor system. J Neurosci 20:1142-1156.

Bittencourt JC, Vaughan J, Arias C, Rissman RA, Vale WW, Sawchenko PE. 1999. Urocortin expression in rat brain: evidence against a pervasive relationship of urocortincontaining projections with targets bearing type $2 \mathrm{CRF}$ receptors. J Comp Neurol 415:285-312.

Braude S. 2000. Dispersal and new colony formation in wild naked mole-rats: evidence against inbreeding as the system of mating. Behav Ecol 11:7-12.

Burda H, Honeycutt RL, Begall S, Locker-Grütjen O, Scharff A. 2000. Are naked and common mole-rats eusocial and if so, why? Behav Ecol Sociobiol 47:293-303.

Castel M, Morris JF. 1988. The neurophysin-containing innervation of the forebrain of the mouse. Neuroscience 24: 937-966.

Chalmers DT, Lovenberg TW, De Souza EB. 1995. Localization of novel corticotropin-releasing factor receptor $\left(\mathrm{CRF}_{1}\right)$ mRNA expression to specific subcortical nuclei in rat brain: comparison with $\mathrm{CRF}_{1}$ receptor mRNA expression. J Neurosci 15:6340-6350.

Champagne F, Diorio J, Sharma S, Meaney MJ. 2001. Naturally occurring variations in maternal behavior in the rat are associated with differences in estrogen-inducible central oxytocin receptors. Proc Natl Acad Sci U S A 98: 12736-12741.

Chang CL, Hsu SY. 2004. Ancient evolution of stress-regulating peptides in vertebrates. Peptides 25:1681-1688.

Chen P, Lin D, Giesler J, Li C. 2011. Identification of urocortin 3 afferent projection to the ventromedial nucleus of the hypothalamus in rat brain. J Comp Neurol 519:20232042.

Chen $\mathrm{Y}$, Brunson KL, Adelmann G, Bender RA, Frotscher M, Baram TZ. 2004. Hippocampal corticotropin releasing hormone: pre- and postsynaptic location and release by stress. Neuroscience 126:533-540.

Chen Y, Andres AL, Frotscher M, Baram TZ. 2012. Tuning synaptic transmission in the hippocampus by stress: the CRH system. Front Cell Neurosci 6:13.

Ciszek D. 2000. New colony formation in the "highly inbred" eusocial naked mole-rat: outbreeding is preferred. Behav Ecol 11:1-6.

Clarke FM, Faulkes CG. 1999. Kin discrimination and female mate choice in the naked mole-rat Heterocephalus glaber. Proc Biol Sci 266:1995-2002.

Cooper MA, Huhman KL. 2005. Corticotropin-releasing factor type II (CRF-sub-2) receptors in the bed nucleus of the stria terminalis modulate conditioned defeat in Syrian hamsters (Mesocricetus auratus). Behav Neurosci 119: 1042-1051.

Dabrowska J, Hazra R, Ahern TH, Guo JD, McDonald AJ, Mascagni F, Muller JF, Young LJ, Rainnie DG. 2011. Neuroanatomical evidence for reciprocal regulation of the 
corticotrophin-releasing factor and oxytocin systems in the hypothalamus and the bed nucleus of the stria terminalis of the rat: implications for balancing stress and affect. Psychoneuroendocrinology 36:1312-1326.

De Souza EB, Insel TR, Perrin MH, Rivier J, Vale WW, Kuhar MJ. 1985. Corticotropin-releasing factor receptors are widely distributed within the rat central nervous system: an autoradiographic study. J Neurosci 5:3189-3203.

Dubois-Dauphin M, Tribollet E, Dreifuss JJ. 1989. Distribution of neurohypophysial peptides in the guinea pig brain. II. An immunocytochemical study of oxytocin. Brain Res 496:66-81.

Ehlers CL, Kaneko WM, Owens MJ, Nemeroff CB. 1993. Effects of gender and social isolation on electroencephalogram and neuroendocrine parameters in rats. Biol Psychiatry 33:358-366.

Faulkes CG, Abbott DH. 1991. Social control of reproduction in breeding and non-breeding male naked mole-rats (Heterocephalus g/aber). J Reprod Fertil 93:427-435.

Faulkes CG, Bennett NC. 2007. African mole-rats: behavioral and ecological diversity. In: Wolff J, Sherman PW, editors. Rodent societies: an ecological and evolutionary perspective. Chicago: The University of Chicago Press. p 427437.

Faulkes CG, Bennett NC. 2013. Plasticity and constraints on social evolution in African mole-rats: ultimate and proximate factors. Philos Trans R Soc Lond B Biol Sci 368: 20120347.

Faulkes CG, Abbott DH, Jarvis JUM. 1990. Social suppression of ovarian cyclicity in captive and wild colonies of naked mole-rats, Heterocephalus glaber. J Reprod Fertil 88: 559-568.

Faulkes CG, Abbott DH, Liddell CE, George LM, Jarvis JUM. 1991. Hormonal and behavioral aspects of reproductive suppression in female naked mole-rats. In: Sherman PW, Jarvis JUM, Alexander RD, editors. The biology of the naked mole-rat. Princeton, NJ: Princeton University Press. p 426-445.

Faulkes CG, Bennett NC, Bruford MW, O’Brien HP, Aguilar GH, Jarvis JUM. 1997. Ecological constraints drive social evolution in the African mole-rats. Proc R Soc Lond B Biol Sci 264:1619-1627.

Faulkes CG, Verheyen E, Verheyen W, Jarvis JU, Bennett NC. 2004. Phylogeographical patterns of genetic divergence and speciation in African mole-rats (family: Bathyergidae). Mol Ecol 13:613-629.

Fernandez Macedo GV, Cladouchos ML, Sifonios L, Cassanelli PM, Wikinski S. 2013. Effects of fluoxetine on CRF and CRF1 expression in rats exposed to the learned helplessness paradigm. Psychopharmacology (Berl) 225:647-659.

Francis DD, Champagne FC, Meaney MJ. 2000. Variations in maternal behaviour are associated with differences in oxytocin receptor levels in the rat. J Neuroendocrinol 12: 1145-1148.

Froc DJ, Christie BR. 2005. Corticotrophin-releasing hormone decreases synaptic transmission in rat sensorimotor cortex in vivo. Neuroscience 134:965-973.

Fu Y, Neugebauer V. 2008. Differential mechanisms of CRF1 and CRF2 receptor functions in the amygdala in painrelated synaptic facilitation and behavior. J Neurosci 28 : 3861-3876.

Funk CK, Koob GF. 2007. A CRF 2 agonist administered into the central nucleus of the amygdala decreases ethanol self-administration in ethanol-dependent rats. Brain Res 1155:172-178.

Fuxe K, Borroto-Escuela DO, Romero-Fernandez W, Ciruela F, Manger P, Leo G, Diaz-Cabiale Z, Agnati LF. 2012. On the role of volume transmission and receptor-receptor interactions in social behaviour: focus on central catecholamine and oxytocin neurons. Brain Res 1476:119131.

Ganem G, Bennett NC. 2004. Tolerance to unfamiliar conspecifics varies with social organization in female African mole-rats. Physiol Behav 82:555-562.

Gehlert DR, Shekhar A, Morin SM, Hipskind PA, Zink C, Gackenheimer SL, Shaw J, Fitz SD, Sajdyk TJ. 2005. Stress and central urocortin increase anxiety-like behavior in the social interaction test via the CRF1 receptor. Eur J Pharmacol 509:145-153.

Getz LL, Carter CS, Gavish L. 1981. The mating system of the prairie vole Microtus ochrogaster: field and laboratory evidence for pair-bonding. Behav Ecol Sociobiol 8:189-194.

Goodson JL, Evans AK, Lindberg L. 2004. Chemoarchitectonic subdivisions of the songbird septum and a comparative overview of septum chemical anatomy in jawed vertebrates. J Comp Neurol 473:293-314.

Grigoriadis DE, Liu XJ, Vaughn J, Palmer SF, True CD, Vale WW, Ling N, De Souza EB. 1996. ${ }^{125}{ }^{-}$-Tyr ${ }^{0}$-sauvagine: a novel high affinity radioligand for the pharmacological and biochemical study of human corticotropin-releasing factor 2 alpha receptors. Mol Pharmacol 50:679-686.

Gruder-Adams S, Getz LL. 1985. Comparison of the mating system and paternal behavior in Microtus ochrogaster and M. pennsylvannicus. J Mammal 66:165-167.

Hahn JD, Kalamatianos T, Coen CW. 2003. Studies on the neuroanatomical basis for stress-induced oestrogenpotentiated suppression of reproductive function: evidence against direct corticotropin-releasing hormone projections to the vicinity of luteinizing hormone-releasing hormone cell bodies in female rats. J Neuroendocrinol 15:732-742.

Haller J, Toth M, Halasz J, De Boer SF. 2006. Patterns of violent aggression-induced brain c-fos expression in male mice selected for aggressiveness. Physiol Behav 88:173-182.

Hauger RL, Grigoriadis DE, Dallman MF, Plotsky PM, Vale WW, Dautzenberg FM. 2003. International Union of Pharmacology. XXXVI. Current status of the nomenclature for receptors for corticotropin-releasing factor and their ligands. Pharmacol Rev 55:21-26.

Heinrichs SC, Koob GF. 2004. Corticotropin-releasing factor in brain: a role in activation, arousal, and affect regulation. J Pharmacol Exp Ther 311:427-440.

Henry B, Vale W, Markou A. 2006. The effect of lateral septum corticotropin-releasing factor receptor 2 activation on anxiety is modulated by stress. J Neurosci 26:9142-9152.

Hikosaka O. 2010. The habenula: from stress evasion to valuebased decision-making. Nat Rev Neurosci 11:503-513.

Hoare SR, Sullivan SK, Fan J, Khongsaly K, Grigoriadis DE. 2005. Peptide ligand binding properties of the corticotropin-releasing factor (CRF) type 2 receptor: pharmacology of endogenously expressed receptors, Gprotein-coupling sensitivity and determinants of CRF2 receptor selectivity. Peptides 26:457-470.

Hostetler CM, Ryabinin AE. 2013. The CRF system and social behavior: a review. Front Neurosci 7:92.

Hsu YW, Wang SD. 2014. Role of the dorsal medial habenula in the regulation of voluntary activity, motor function, hedonic state, and primary reinforcement. J Neurosci 34: $11366-11384$.

Huchon D, Douzery EJ. 2001. From the Old World to the New World: a molecular chronicle of the phylogeny and biogeography of hystricognath rodents. Mol Phylogenet Evol 20:238-251.

Insel TR, Shapiro LE. 1992. Oxytocin receptor distribution reflects social organization in monogamous and polygamous voles. Proc Natl Acad Sci U S A 89:5981-5985. 
Iredale PA, Terwilliger R, Widnell KL, Nestler EJ, Duman RS. 1996. Differential regulation of corticotropin-releasing factor 1 receptor expression by stress and agonist treatments in brain and cultured cells. Mol Pharmacol 50:1103-1110.

Jarvis JUM. 1981. Eusociality in a mammal: cooperative breeding in naked mole-rat colonies. Science 212:571-573.

Jarvis JUM. 1991. Reproduction of naked mole-rats. In: Sherman PW, Jarvis JUM, Alexander RD, editors. The biology of the naked mole-rat. Princeton, NJ: Princeton University Press. p 384-425.

Jarvis JUM, Bennett NC. 1991. Ecology and behavior of the family Bathyergidae. In: Sherman PW, Jarvis JUM, Alexander RD, editors. The biology of the naked molerat. Princeton, NJ: Princeton University Press. p 66-96.

Jarvis JU, O'Riain MJ, Bennett NC, Sherman PW. 1994. Mammalian eusociality: a family affair. Trends Ecol Evol 9:47-51.

Jochman KA, Newman SM, Kalin NH, Bakshi VP. 2005. Corticotropin-releasing factor-1 receptors in the basolateral amygdala mediate stress-induced anorexia. Behav Neurosci 119:1448-1458.

Justice NJ, Yuan ZF, Sawchenko PE, Vale W. 2008. Type 1 corticotropin-releasing factor receptor expression reported in BAC transgenic mice: implications for reconciling ligand-receptor mismatch in the central corticotropinreleasing factor system. J Comp Neurol 511:479-496.

Kalamatianos T, du Toit L, Hrabovszky E, Kalló I, Marsh PJ, Bennett NC, Coen CW. 2005. Characterization of gonadotrophin-releasing hormone precursor cDNA in the Old World mole-rat Cryptomys hottentotus pretoriae: high degree of identity with the New World guinea pig sequence. J Neuroendocrinol 17:265-268.

Kalamatianos T, Faulkes CG, Oosthuizen MK, Poorun R, Bennett NC, Coen CW. 2010. Telencephalic binding sites for oxytocin and social organization: a comparative study of eusocial naked mole-rats and solitary cape mole-rats. J Comp Neurol 518:1792-1813.

Kim EB, Fang X, Fushan AA, Huang Z, Lobanov AV, Han L, Marino SM, Sun X, Turanov AA, Yang P, Yim SH, Zhao X, Kasaikina MV, Stoletzki N, Peng C, Polak P, Xiong Z, Kiezun A, Zhu Y, Chen Y, Kryukov GV, Zhang Q, Peshkin L, Yang L, Bronson RT, Buffenstein R, Wang B, Han C, Li Q, Chen L, Zhao W, Sunyaev SR, Park TJ, Zhang G, Wang J, Gladyshev VN. 2011. Genome sequencing reveals insights into physiology and longevity of the naked mole rat. Nature 479:223-227.

Kollack-Walker S, Watson SJ, Akil H. 1997. Social stress in hamsters: defeat activates specific neurocircuits within the brain. J Neurosci 17:8842-8855.

Kovacs KJ. 2013. CRH: the link between hormonal-, metabolicand behavioral responses to stress. J Chem Neuroanat $54: 25-33$

Lacey EA, Sherman PW. 1991. Social organization of naked mole-rat colonies: evidence for divisions of labor. In: Sherman PW, Jarvis JUM, Alexander RD, editors. The biology of the naked mole-rat. Princeton, NJ: Princeton University Press. $p$ 275-336.

Landgraf R, Frank E, Aldag JM, Neumann ID, Sharer CA, Ren X, Terwilliger EF, Niwa M, Wigger A, Young LJ. 2003. Viral vector-mediated gene transfer of the vole $\mathrm{V} 1$ a vasopressin receptor in the rat septum: improved social discrimination and active social behaviour. Eur J Neurosci 18:403-411.

Le Comber SC, Spinks AC, Bennett NC, Jarvis JU, Faulkes CG. 2002. Fractal dimension of African mole-rat burrows. Can J Zool 80:436-441.

Lewis K, Li C, Perrin MH, Blount A, Kunitake K, Donaldson C, Vaughan J, Reyes TM, Gulyas J, Fischer W, Bilezikjian L, Rivier J, Sawchenko PE, Vale WW. 2001. Identification of urocortin III, an additional member of the corticotropin- releasing factor (CRF) family with high affinity for the CRF2 receptor. Proc Natl Acad Sci U S A 98:7570-7575.

Li C, Vaughan J, Sawchenko PE, Vale WW. 2002. Urocortin IIIimmunoreactive projections in rat brain: partial overlap with sites of type 2 corticotrophin-releasing factor receptor expression. J Neurosci 22:991-1001.

Li C, Chen P, Vaughan J, Blount A, Chen A, Jamieson PM, Rivier J, Smith MS, Vale W. 2003. Urocortin III is expressed in pancreatic beta-cells and stimulates insulin and glucagon secretion. Endocrinology 144:3216-3224.

Liebsch G, Landgraf R, Gerstberger R, Probst JC, Wotjak CT, Engelmann M, Holsboer F, Montkowski A. 1995. Chronic infusion of a $\mathrm{CRH} 1$ receptor antisense oligodeoxynucleotide into the central nucleus of the amygdala reduced anxiety-related behavior in socially defeated rats. Regul Pept 59:229-239.

Lim MM, Murphy AZ, Young LJ. 2004. Ventral striatopallidal oxytocin and vasopressin $\mathrm{V} 1 \mathrm{a}$ receptors in the monogamous prairie vole (Microtus ochrogaster). J Comp Neurol 468:555-570.

Lim MM, Nair HP, Young LJ. 2005. Species and sex differences in brain distribution of corticotropin-releasing factor receptor subtypes 1 and 2 in monogamous and promiscuous vole species. J Comp Neurol 487:75-92.

Lim MM, Tsivkovskaia NO, Bai Y, Young LJ, Ryabinin AE. 2006. Distribution of corticotropin-releasing factor and urocortin 1 in the vole brain. Brain Behav Evol 68:229-240.

Lim MM, Liu Y, Ryabinin AE, Bai Y, Wang Z, Young LJ. 2007. CRF receptors in the nucleus accumbens modulate partner preference in prairie voles. Horm Behav 51:508-515.

Maras PM, Baram TZ. 2012. Sculpting the hippocampus from within: stress, spines, and CRH. Trends Neurosci 35:315-324.

Mclntyre CK, McGaugh JL, Williams CL. 2012. Interacting brain systems modulate memory consolidation. Neurosci Biobehav Rev 36:1750-1762.

Meng QY, Chen XN, Tong DL, Zhou JN. 2011. Stress and glucocorticoids regulated corticotropin releasing factor in rat prefrontal cortex. Mol Cell Endocrinol 342:54-63.

Merchenthaler I. 1984. Corticotropin releasing factor (CRF)-like immunoreactivity in the rat central nervous system. Extrahypothalamic distribution. Peptides 5(Suppl 1):53-69.

Merchenthaler I, Vigh S, Petrusz P, Schally AV. 1982. Immunocytochemical localization of corticotropin-releasing factor (CRF) in the rat brain. Am J Anat 165:385-396.

Merlo Pich E, Lorang M, Yeganeh M, Rodriguez de Fonseca F, Raber J, Koob GF, Weiss F. 1995. Increase of extracellular corticotropin-releasing factor-like immunoreactivity levels in the amygdala of awake rats during restraint stress and ethanol withdrawal as measured by microdialysis. J Neurosci 15:5439-5447.

Nair HP, Gutman AR, Davis M, Young LJ. 2005. Central oxytocin, vasopressin, and corticotropin-releasing factor receptor densities in the basal forebrain predict isolation potentiated startle in rats. J Neurosci 25:11479-11488.

Narins PM, Reichman OJ, Jarvis JU, Lewis ER. 1992. Seismic signal transmission between burrows of the Cape molerat, Georychus capensis. J Comp Physiol A 170:13-21.

Olazabal DE, Young LJ. 2006. Species and individual differences in juvenile female alloparental care are associated with oxytocin receptor density in the striatum and the lateral septum. Horm Behav 49:681-687.

Oosthuizen MK, Bennett NC, Coen CW. 2008. An immunohistochemical study of the gonadotrophin-releasing hormone 1 system in solitary Cape mole-rats, Georychus capensis, and social Natal mole-rats, Cryptomys hottentotus natalensis. Neuroscience 157:164-173.

O'Riain MJ, Faulkes CG. 2008. African mole-rats: eusociality, relatedness and ecological constraints. In: Heinze J, Korb 
J, editors. Ecology of social evolution. Berlin: Springer Verlag. p 205-220.

O'Riain MJ, Jarvis JU. 1997. Colony member recognition and xenophobia in the naked mole-rat. Anim Behav 53:487-498.

Pournajafi-Nazarloo H, Partoo L, Yee J, Stevenson J, Sanzenbacher L, Kenkel W, Mohsenpour SR, Hashimoto $\mathrm{K}$, Carter CS. 2011. Effects of social isolation on mRNA expression for corticotrophin-releasing hormone receptors in prairie voles. Psychoneuroendocrinology 36:780-789.

Primus RJ, Yevich E, Baltazar C, Gallager DW. 1997. Autoradiographic localization of CRF1 and CRF2 binding sites in adult rat brain. Neuropsychopharmacology 17:308-316.

Radulovic J, Ruhmann A, Liepold T, Spiess J. 1999. Modulation of learning and anxiety by corticotropin-releasing factor (CRF) and stress: differential roles of CRF receptors 1 and 2. J Neurosci 1999:5016-5025.

Reyes TM, Lewis K, Perrin MH, Kunitake KS, Vaughan J, Arias CA, Hogenesch JB, Gulyas J, Rivier J, Vale WW, Sawchenko PE. 2001. Urocortin II: a member of the corticotropin-releasing factor (CRF) neuropeptide family that is selectively bound by type 2 CRF receptors. Proc Natl Acad Sci U S A 98:2843-2848.

Rivier J, Gulyas J, Kirby D, Low W, Perrin MH, Kunitake K, DiGruccio M, Vaughan J, Reubi JC, Waser B, Koerber SC, Martinez V, Wang W, Tache Y, Vale W. 2002. Potent and long-acting corticotropin releasing factor (CRF) receptor 2 selective peptide competitive antagonists. J Med Chem 45:4737-4747.

Robison CL, Meyerhoff JL, Saviolakis GA, Chen WK, Rice KC, Lumley LA. 2004. A CRH1 antagonist into the amygdala of mice prevents defeat-induced defensive behavior. Ann N Y Acad Sci 1032:324-327.

Rominger DH, Rominger CM, Fitzgerald LW, Grzanna R, Largent BL, Zaczek R. 1998. Characterization of ${ }^{125}$ I] sauvagine binding to $\mathrm{CRH} 2$ receptors: membrane homogenate and autoradiographic studies. J Pharmacol Exp Ther 286:459-468.

Ross HE, Cole CD, Smith Y, Neumann ID, Landgraf R, Murphy AZ, Young LJ. 2009. Characterization of the oxytocin system regulating affiliative behavior in female prairie voles. Neuroscience 162:892-903.

Sahuque LL, Kullberg EF, McGeehan AJ, Kinder JR, Hicks MP, Blanton MG, Janak PH, Olive MF. 2006. Anxiogenic and aversive effects of corticotropin-releasing factor (CRF) in the bed nucleus of the stria terminalis in the rat: role of CRF receptor subtypes. Psychopharmacology (Berl) 186:122-132.

Salo AL, Shapiro LE, Dewsbury DA. 1993. Affiliative behavior in different species of voles (Microtus). Psychol Rep 72: 316-318.

Sananbenesi F, Fischer A, Schrick C, Spiess J, Radulovic J. 2003. Mitogen-activated protein kinase signaling in the hippocampus and its modulation by corticotropinreleasing factor receptor 2: a possible link between stress and fear memory. J Neurosci 23:11436-11443.

Sanchez MM, Young LJ, Plotsky PM, Insel TR. 1999. Autoradiographic and in situ hybridization localization of corticotropin-releasing factor 1 and 2 receptors in nonhuman primate brain. J Comp Neurol 408:365-377.

Schulz DW, Mansbach RS, Sprouse J, Braselton JP, Collins J, Corman M, Dunaiskis A, Faraci S, Schmidt AW, Seeger T, Seymour P, Tingley FD 3rd, Winston EN, Chen YL, Heym J. 1996. CP-154,526: a potent and selective nonpeptide antagonist of corticotropin releasing factor receptors. Proc Natl Acad Sci U S A 93:10477-10482.
Seidel K, Poeggel G, Holetschka R, Helmeke C, Braun K. 2011. Paternal deprivation affects the development of corticotrophin-releasing factor-expressing neurones in prefrontal cortex, amygdala and hippocampus of the biparental Octodon degus. J Neuroendocrinol 23:1166-1176.

Shapiro LE, Dewsbury DA. 1990. Differences in affiliative behavior, pair bonding, and vaginal cytology in two species of vole (Microtus ochrogaster and M. montanus). J Comp Psychol 104:268-274.

Shekhar A, Truitt W, Rainnie D, Sajdyk T. 2005. Role of stress, corticotrophin releasing factor (CRF) and amygdala plasticity in chronic anxiety. Stress 8:209-219.

Sherman PW, Jarvis JUM, Alexander RD. 1991. The biology of the naked mole-rat. Princeton, NJ: Princeton University Press.

Swanson LW, Sawchenko PE, Rivier J, Vale WW. 1983. Organization of ovine corticotropin-releasing factor immunoreactive cells and fibers in the rat brain: an immunohistochemical study. Neuroendocrinology 36:165-186.

Tagliaferro P, Morales M. 2008. Synapses between corticotropinreleasing factor-containing axon terminals and dopaminergic neurons in the ventral tegmental area are predominantly glutamatergic. J Comp Neurol 506:616-626.

Tran L, Schulkin J, Greenwood-Van Meerveld B. 2014. Importance of CRF receptor-mediated mechanisms of the bed nucleus of the stria terminalis in the processing of anxiety and pain. Neuropsychopharmacology 39:2633-2645.

Tribollet E, Barbaris C, Dubois-Dauphin M, Dreifuss JJ. 1992. Localization and characterization of binding sites for vasopressin and oxytocin in the brain of the guinea pig. Brain Res 589:15-23.

Ugolini A, Sokal DM, Arban R, Large CH. 2008. CRF1 receptor activation increases the response of neurons in the basolateral nucleus of the amygdala to afferent stimulation. Front Behav Neurosci 2:2.

van Pett K, Viau V, Bittencourt JC, Chan RKW, Li HY, Arias C, Prins GS, Perrin M, Vale W, Sawchenko PE. 2000. Distribution of mRNAs encoding CRF receptors in brain and pituitary of rat and mouse. J Comp Neurol 428:191-212.

Viswanath H, Carter AQ, Baldwin PR, Molfese DL, Salas R. 2013. The medial habenula: still neglected. Front Hum Neurosci 7:931.

von Wolff G, Avrabos C, Stepan J, Wurst W, Deussing JM, Holsboer F, Eder M. 2011. Voltage-sensitive dye imaging demonstrates an enhancing effect of corticotropin-releasing hormone on neuronal activity propagation through the hippocampal formation. J Psychiatr Res 45:256-261.

Wittmann G, Fuzesi T, Liposits Z, Lechan RM, Fekete C. 2009. Distribution and axonal projections of neurons coexpressing thyrotropin-releasing hormone and urocortin 3 in the rat brain. J Comp Neurol 517:825-840.

Yu C, Li Y, Holmes A, Szafranski K, Faulkes G, Coen CW, Buffenstein R, Platzer M, de Magalhães JP, Church GM. 2011. RNA sequencing reveals differential expression of mitochondrial and oxidation reduction genes in the long-lived naked mole-rat when compared to mice. PLoS One 6:e26729.

Zhou S, Holmes MM, Forger NG, Goldman BD, Lovern MB, Caraty A, Kallo I, Faulkes CG, Coen CW. 2013. Socially regulated reproductive development: analysis of $\mathrm{GnRH}-1$ and kisspeptin neuronal systems in cooperatively breeding naked mole-rats (Heterocephalus glaber). J Comp Neurol 521:3003-3029.

Zieba B, Grzegorzewska M, Branski P, Domin H, Wieronska JM, Hess G, Smialowska M. 2008. The behavioural and electrophysiological effects of CRF in rat frontal cortex. Neuropeptides 42:513-523. 